\title{
Industrial Applications of Soft Computing: A Review
}

\author{
YASUHIKO DOTE AND SEPPO J. OVASKA, SENIOR MEMBER, IEEE
}

Invited Paper

Soft computing (SC) is an evolving collection of methodologies, which aims to exploit tolerance for imprecision, uncertainty, and partial truth to achieve robustness, tractability, and low cost. SC provides an attractive opportunity to represent the ambiguity in human thinking with real life uncertainty. Fuzzy logic (FL), neural networks $(N N)$, and evolutionary computation (EC) are the core methodologies of soft computing. However, FL, NN, and EC should not be viewed as competing with each other, but synergistic and complementary instead. SC has been theoretically developed for the past decade, since L. A. Zadeh proposed the concept in the early 1990s. Soft computing is causing a paradigm shift (breakthrough) in engineering and science fields since it can solve problems that have not been able to be solved by traditional analytic methods [tractability (TR)]. In addition, SC yields rich knowledge representation (symbol and pattern), flexible knowledge acquisition (by machine learning from data and by interviewing experts), and flexible knowledge processing (inference by interfacing between symbolic and pattern knowledge), which enable intelligent systems to be constructed at low cost [high machine intelligence quotient (HMIQ)]. This paper reviews applications of SC in several industrial fields to show the various innovations by TR, HMIQ, and low cost in industries that have been made possible by the use of SC. Our paper intends to remove the gap between theory and practice and attempts to learn how to apply soft computing practically to industrial systems from examples/analogy reviewing many application papers.

Keywords-Chaos computing, computational intelligence, evolutionary computation, fuzzy logic, immune networks, industrial applications, neural networks, soft computing.

\section{INTRODUCTION}

In 1987, fuzzy control was successfully applied in industrial plants in Japan. In the late 1980s, neuro-control was used for robot arms (including the robot arm of the space shuttle, chemical processes, continuous production of high-quality

Manuscript received January 15, 2001; revised April 9, 2001.

Y. Dote is with the Muroran Institute of Technology, Department of Computer Science and Systems Engineering, Muroran 050-8585, Japan (e-mail: dote@csse.muroran-it.ac.jp).

S. J. Ovaska is with the Helsinki University of Technology, Institute of Intelligent Power Electronics, FIN-02150 Espoo, Finland (e-mail: seppo.ovaska@hut.fi).

Publisher Item Identifier S 0018-9219(01)07606-X. parts, and aerospace applications) in the U.S. [1]. In 1991, the Berkeley Initiative in Soft Computing (BISC) was established as an ILP (Industrial Liaison Program), with L. A. Zadeh as its director. Since the establishment of BISC, researchers throughout the world have been studying soft computing, i.e., the fusion of fuzzy logic (FL), neural networks (NN), and evolutionary computation (EC) [2]. The term computational intelligence, as defined by Zadeh, is the combination of soft computing and numerical processing. This term was first used in 1990 by the IEEE Neural Networks Council. Three IEEE International Workshops on Soft Computing in Industry have been held in Muroran, Japan, in 1993, 1996, and 1999, with Zadeh as plenary speaker each time [3]-[5]. The first workshop put emphasis on the fusion of neural networks and fuzzy logic. In the second workshop, evolutionary computation, chaos computing, and immune networks were discussed. The third workshop focused on cognitive distributed artificial intelligence (human-like information processing) [5] and reactive distributed artificial intelligence (bioinformatic information processing) [78].

The papers from the above workshops, as well as from the related IEEE Transactions using the IEEE Xplore, and other related journals over the past ten years are reviewed here in order to show industrial innovations that have taken place using soft computing. In this paper, industrial innovations using soft computing are discussed in Section II, and applications to the aerospace industry, communications systems, consumer appliances, electric power systems, manufacturing automation and robotics, power electronics and motion control, process engineering, and transportation are discussed in Sections III-X. Finally, future opportunities are outlined in Section XI and conclusions are presented in Section XII.

\section{INDUSTRIAL INNOVATION USING SOFT COMPUTING}

Soft computing (SC) was proposed for construction of new generation artificial intelligence (high machine intelligence quotient (HMIQ), human-like information processing) and 
for solving nonlinear and mathematically unmodeled systems (tractability) (TR) [3]. In addition, SC can be implemented at low cost (LC). SC is the fusion or combination of fuzzy, neuro, and evolutional computings [40].

Later, chaos computing and immune networks were added [4] to explain so-called complex systems [2], cognitive distributed artificial intelligence, and reactive distributed artificial intelligence [123].

It has been proven that nonlinear mapping obtained by neural networks can be approximated to any desired accuracy by the use of fuzzy systems [6]. As neural networks have flexible learning capabilities, it is possible to develop nonlinear models using only input-output (I/O) data. However, it is often cumbersome to fine-tune the modeling accuracy of neural networks, because it may be difficult to explain logically the cause and result in the excitation-response relationships. On the other hand, fuzzy systems provide clear advantages in knowledge representation and acquisition. For example, knowledge is easily introduced in parallel to an adaptive fuzzy neural network by constructing a hierarchical diagnosis structure and modifying rules by available structured knowledge [96], or modifying and adjusting fuzzy inference for pattern recognition with lack of input data by some complementary knowledge [7]. Fuzzy systems, however, have been missing adaptation capabilities for a long time [1]. Jang and Sun have shown that under the condition of minor restrictions, functional behaviors of radial basis function networks and fuzzy inference systems are the same [8]. On the other hand, local models in blended multiple model structures for nonlinear systems (fast fuzzy neural networks) have been recently investigated [9]-[11], [93].

For example, [93] presents type-I fuzzy systems implemented using Gaussian radial basis function neural networks as local models in blended model structures for nonlinear systems. This fuzzy neural network is actually an extended radial basis function network that is obtained by replacing the output layer weights with a linear function of the network inputs. Each neuron represents a local linear model with its corresponding validity function (membership function). Furthermore, the radial basis function network is normalized like fuzzy membership functions. The side effects of normalizing should be considered, as all validity functions for a specific input combination sum up to one [12]. The Gaussian validity functions determine the regions of the input space where each neuron is active. The input space becomes larger when dynamic systems are represented by these networks. A fast fuzzy neural network with general parameter learning is developed. It is especially suitable for real-time fault diagnosis since what we have to do is to only observe changes in a general parameter. It was implemented with a digital signal processor (DSP) integrated RISC machine [93]. Recurrent fuzzy neural networks are recommended as a means to reduce the size of the input space [13]. They are able to yield adaptive self-tuning, self-organizing, and automated design functions for nonlinear systems and systems for which suitable mathematical models are not obtained. They are also used for cognitive (fuzzy decision tree, etc.) and reactive (multiagent system coordination, etc.) decision making. DSPs and advanced computer systems are at present utilized to im- plement soft computing. Neuro computing and evolutionary computation usually need a lot of computational time, which is the disadvantage of the implementation of soft computing. Recently developed fuzzy neural networks enable solutions to be obtained for problems that have not been able to be solved by traditional analytical methods (hard computing) [14], since function approximation is used rather than parameter optimization (TR). Tractability enables industrial systems to become increasingly innovative.

Evolutionary computation has been developed and modified for applications of optimization for large-scale and complex systems as shown later in this paper. Fogel proposed intelligence based on bioinformatics [78]. Data mining, for which soft computing is an effective and a promising approach, has been attracting the attention of researchers in industry [60]. Data mining is expected to be applied to largescale process plants and electric power systems for decision support and optimization (TR).

Soft computing has recently been playing an important role in advanced knowledge processing. An advanced learning method using a combination of perception and motion has been introduced. Emergent, self-organizing, reflective, and interactive (among human beings, environment, and artificial intelligence) knowledge processing is considered by using soft computing and by borrowing ideas from bio-information processing [79]. Soft computing provides rich knowledge representation (symbol and pattern), flexible knowledge acquisition (by learning from data and by interviews with experts), and knowledge processing (inference by interface between symbolic and pattern knowledge). Therefore, it is straightforward to construct low-cost intelligent systems. The various kinds of artificial intelligence (cognitive and reactive AI) make industrial systems intelligent. Such an intelligent system has adaptive, autonomous, decision support, optimization, and emergent functions (HMIQ). This HMIQ enables innovations in industry. This innovation potential is discussed in our paper, by surveying a representative set of application papers in various kinds of application fields. As shown in Table 1, soft computing has been used considerably in human-related fields such as, manufacturing automation and robotics, and transportation. The proportion of SC publications in different fields of application from 1990 to 1999 is illustrated in Fig. 1.

\section{AEROSPACE APPLICATIONS}

\section{A. General View}

In the early 1990s, Werbos developed nonlinear optimal neuro control (adaptive critics). It has been applied to aerospace and aircraft control systems [1]. Soft computing (neuro, fuzzy, and evolutionary computings) is used for aerospace systems because of the high degrees of nonlinearity, uncertainty, and complexity of these problems and because of the involvement of human beings [18].

\section{B. Application Fields}

Neuro control is very effective in aerodynamics, since aerodynamics characteristics are usually highly nonlinear 
Table 1.

Number of Published Papers in Different Fields of Application During 1990-1999

(Based on the IEEE Xplore)

\begin{tabular}{|c|c|c|c|c|c|c|c|c|c|c|c|}
\hline Field of Application & $\%$ & 1990 & 1991 & 1992 & 1993 & 1994 & 1995 & 1996 & 1997 & 1998 & 1999 \\
\hline \multirow{2}{*}{$\begin{array}{c}\text { Aerospace } \\
\text { Applications }\end{array}$} & $\overline{\overline{\mathrm{A}}}$ & $\overline{2.8}$ & 3.9 & $\overline{4.2}$ & $\overline{5.0}$ & $\overline{\overline{7.1}}$ & $\overline{5.6}$ & 4.6 & $\overline{5.4}$ & $\overline{4.8}$ & $\overline{4.9}$ \\
\hline & SC & 2.4 & 1.8 & 2.2 & 2.3 & 2.5 & 1.8 & 1.8 & 1.9 & 1.7 & 1.3 \\
\hline \multirow{2}{*}{$\begin{array}{l}\text { Communications } \\
\text { Systems }\end{array}$} & $\mathrm{A}$ & 2.6 & 2.8 & 3.1 & 4.1 & 3.5 & 3.7 & 3.5 & 4.2 & 3.9 & 2.6 \\
\hline & SC & 8.5 & 5.2 & 6.1 & 9.1 & 6.0 & 6.6 & 6.2 & 7.5 & 7.4 & 4.4 \\
\hline \multirow{2}{*}{$\begin{array}{l}\text { Electric Power } \\
\text { Systems }\end{array}$} & $\mathrm{A}$ & 0.5 & 0.9 & 2.1 & 1.2 & 2.8 & 2.5 & 4.0 & 4.1 & 3.3 & 3.9 \\
\hline & SC & 0.5 & 0.5 & 0.9 & 0.8 & 1.1 & 1.2 & 1.9 & 1.5 & 1.3 & 1.4 \\
\hline \multirow{2}{*}{$\begin{array}{l}\text { Manufacturing Auto- } \\
\text { mation and Robotics }\end{array}$} & $\mathrm{A}$ & 4.6 & 8.0 & 9.6 & 9.7 & 12.9 & 13.3 & 14.9 & 14.5 & 15.3 & 13.9 \\
\hline & $\mathrm{SC}$ & $5 . \overline{3}$ & 6.5 & 8.8 & 8.1 & $\overline{9.2}$ & $\overline{9.5}$ & 9.9 & 10.0 & 11.3 & 8.8 \\
\hline \multirow{2}{*}{$\begin{array}{l}\text { Power Electronics } \\
\text { and Motion Control }\end{array}$} & $\mathrm{A}$ & 2.2 & 2.6 & 5.5 & 5.8 & 5.8 & 6.5 & 6.0 & 7.2 & 6.2 & 5.7 \\
\hline & $\mathrm{SC}$ & 1.5 & 1.0 & 2.8 & $\overline{3.8}$ & 2.4 & 3.4 & 3.1 & 3.0 & 3.1 & 2.5 \\
\hline \multirow{2}{*}{ Transportation } & $\mathrm{A}$ & 5.8 & 5.9 & 8.6 & 8.3 & 9.9 & 12.0 & 9.8 & 10.7 & 10.6 & 11.8 \\
\hline & SC & 3.1 & 1.7 & 2.4 & 3.5 & $\overline{3.3}$ & 3.9 & 3.5 & 3.6 & 3.6 & 3.8 \\
\hline
\end{tabular}

A: (Number of papers in which soft computing is used in each field) / (Total number of papers in each field) *100\%. SC: (Number of papers in which soft computing is used in each field) / (Number of papers in which soft computing is used in all fields) * $100 \%$.

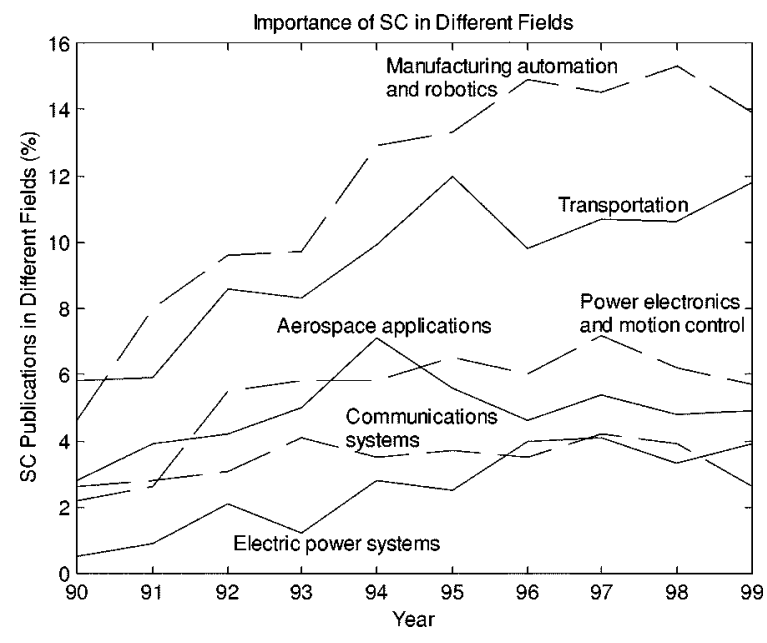

Fig. 1. Proportion (\%) of soft computing publications in different fields of application during 1990-1999.

and uncertain (varying), and data is available for learning. Evolutionary computation is useful when optimization solutions for complex systems are required. Since these applications sometimes involve human operators, fuzzy approaches that provide excellent interface methods with human beings are useful [18]. A summary of application of $\mathrm{SC}$ in aerospace is given in Table 2.

\section{Aircrafts and Air Traffic}

Calise proposed the use of neural networks for flight control of an aircraft. One network is used to obtain inverse dynamic models off-line, and another neural network is used on-line to behave as an inverse controller [15].

Napolitano et al. constructed a neural and fuzzy virtual flight recorder that could record aircraft control surface deflections. A neural network simulator is interfaced with the recorders. The outputs of these two reconstructors are the control surface deflections that minimize a performance index based on the differences between the available data and the output from the simulator [16].
Schneider et al. presented an approach that integrates human interaction with simulations and genetic algorithms for the realistic repair-time analysis problem in airbase logistics. These problems are difficult-to-quantify issues with conventional computation [17].

\section{Spacecrafts}

Berenji proposed the application of soft computing to NASA space projects such as the orbital operations of the space shuttle, including attitude control and rendezvous/docking operations [18].

Alvarez et al. used fuzzy approaches for continuous driving of long-range autonomous planetary micro-rovers, which required maximization of the range and number of interesting scientific sites visited during a limited lifetime. They used a complete set of techniques including fuzzy-based control, real-time reasoning, and fast and robust rover position estimation based on odometry, angular rate sensing, and efficient stereo vision [19].

\section{COMMUNiCATIONS Systems}

\section{A. General View}

Since communication systems involve human beings, soft computing can be effectively applied to such systems. Soft computing enables solutions to be obtained for problems that have not been able to be solved satisfactorily by hard computing methods.

\section{B. Application Fields}

Chaos computing is effectively used for modulation and synchronization of spread sequences in digital communication systems. Neuro-fuzzy approaches are utilized for equalizers and data compression. Network topologies are determined using evolutionary computation. Soft computing is also expected to play an important role in the development of wireless communication systems. An outline of applications of soft computing to communications systems is given in Table 3. 
Table 2 .

Summary of Applications of Soft Computing in Aerospace Applications

\begin{tabular}{|c|c|c|c|}
\hline Application & Characteristics & SC Component & References \\
\hline Aircraft and Air Traffic & $\begin{array}{l}\text { - Numerical results based on 6-DOF simula- } \\
\text { tions of a high performance aircraft using two } \\
\text { neural networks as a part of a flight control } \\
\text { system architecture are presented to show its } \\
\text { potential capability. } \\
\text { - Typical flight data recorders on commercial } \\
\text { airliners do not record the aircraft control sur- } \\
\text { face deflections. The present method provides } \\
\text { accurate reconstruction of deflection with NN } \\
\text { and FL. } \\
\text { - Airbase logistics planning is a difficult-to- } \\
\text { quantify and complex issue with hard com- } \\
\text { puting. This mehtod gives an optimal realistic } \\
\text { repair time schedule using genetic algorithms. }\end{array}$ & $\begin{array}{c}\text { NN } \\
(\mathrm{TR}) \\
\\
\text { NN, FL } \\
(\mathrm{TR}, \mathrm{LC}) \\
\\
\text { EC } \\
\text { (HMIQ) }\end{array}$ & {$[17]$} \\
\hline Spacecraft & $\begin{array}{l}\text { - The orbital operations of the Space Shut- } \\
\text { tle are achieved by soft computing extracting } \\
\text { knowledge from experience. } \\
\text { - This paper proposes a fuzzy reactive pilot- } \\
\text { ing for continuous driving of long-range au- } \\
\text { tonomous planetary micro-rovers. } \\
\text { - Optimal nonlinear neuro control (adaptive } \\
\text { critics) is successfully applied to aerospace and } \\
\text { aircraft control systems. }\end{array}$ & $\begin{array}{c}\text { NN, FL } \\
\text { (HMIQ) } \\
\text { FL } \\
(\mathrm{TR}) \\
\text { NN } \\
(\mathrm{TR})\end{array}$ & $\begin{array}{l}{[18]} \\
{[19]} \\
{[1]}\end{array}$ \\
\hline
\end{tabular}

TR: Tractability, HMIQ: High Machine Intelligence Quotient, LC: Low Cost

\section{Data Communications}

Kolumban et al. applied chaos computation to a synchronized coherent receiver, which has advantages over noncoherent ones in terms of noise performance and bandwidth efficiency. The performance of chaos computing-based communications systems is compared with those of conventional ones in [20].

Patra et al. developed a fuzzy implemented channel equalizer that showed performance close to that of an optimal equalizer with a substantial reduction in computational complexity [21].

Cramer et al. developed a neuro post-processor that could be used for any existing video compression scheme. Their approach was to interpolate video sequences and compensate for frames that may have been lost or deliberately dropped [22].

Jou et al. proposed an online lossless data compression method using an adaptive fuzzy-tuning modeler with fuzzy inference. The performance was better than that of other lossless coding schemes and satisfactory for various types of source data [23].

\section{Communication Networks}

Gelenbe et al. proposed intelligent techniques and used them in high-speed networks. The use of neural networks for multimedia traffic prediction for the purpose of traffic shaping or reserving resources was shown to be much more accurate and simpler than traditional linear predictors. Similarly, it was shown that the extraction of features and rules from incomplete data sets to compute the bandwidth or anticipate congestion episodes in switches could be performed simply and effectively using neuro-fuzzy approaches. The uncertainties in estimating statistical parameters were also overcome through the use of several neuro and fuzzy solutions. The advantages of intelligent techniques, notably learning from experience, scalability, adaptability, and ability to extract rules without the need for detailed or precise mathematical modeling, are numerous. Genetic algorithms provided optimal solutions for channel reuse in multiple access telecommunication networks and in other communication networks [24].

Chakraborty et al. proposed an efficient genetic algorithm for channel assignment problems in cellular radio networks. The task was to assign channels to different cells in an efficient way: a minimum frequency band is used and, at the same time, interference among cells from different cells is practically avoided. An improved genetic algorithm has also been developed [25].

Dengiz et al. presented a genetic algorithm with specialized encoding, initialization, and local search operators to optimize the design of communication network topologies [26].

Gao et al. presented a neural network-based predictor for received power level prediction in direct sequence code division multiple access (DS-CDMA) systems. Their predictor consists of an adaptive linear element followed by a multilayer perceptron. Besides, the neural network topologies are optimized using the predictive minimum description length (PMDL) method, for reducing computational complexity and maximizing the generalization capability [27]. 
Table 3.

Summary of Applications of Soft Computing in Communications Systems

\begin{tabular}{|c|c|c|c|}
\hline Application & Characteristics & SC Component & References \\
\hline Data Communications & $\begin{array}{l}\text { - A digital chaotic communication system is } \\
\text { proposed. A coherent synchronization receiver } \\
\text { which has the advantages over non-coherent } \\
\text { one in terms of noise performance and band- } \\
\text { width efficiency is presented. } \\
\text { - A FL-based equalizer is developed. It pro- } \\
\text { vides performance close to the optimal equal- } \\
\text { izer with a substantial reduction in computa- } \\
\text { tional complexity. } \\
\text { - The use of neural networks as post- } \\
\text { processors for any existing video compression } \\
\text { scheme is proposed. } \\
\text { - An adaptive fuzzy-tuning modeler for data } \\
\text { compression is proposed. }\end{array}$ & $\begin{array}{c}\text { CC } \\
(\mathrm{TR}) \\
\\
\mathrm{FL} \\
(\mathrm{TR}) \\
\\
\mathrm{NN} \\
(\mathrm{TR}) \\
\mathrm{FL} \\
(\mathrm{TR})\end{array}$ & $\begin{array}{l}{[21]} \\
{[22]} \\
{[23]}\end{array}$ \\
\hline Communication Networks & $\begin{array}{l}\text { - Multi-media traffic prediction with NNs, fea- } \\
\text { ture and rule extraction with a neuro-fuzzy } \\
\text { approach, network structure determination } \\
\text { with EC and others in high speed networks } \\
\text { are proposed. } \\
\text { - EC is proposed to solve channel assignment } \\
\text { problem in cellular radio networks. } \\
\text { - An improved genetic algorithm is proposed } \\
\text { to optimize the design of communication net- } \\
\text { work topologies. } \\
\text { - A neural network-based estimator for re- } \\
\text { ceived power level in direct sequence code di- } \\
\text { vision multiple access systems is developed. }\end{array}$ & $\begin{array}{l}\mathrm{FL}, \mathrm{NN}, \mathrm{EC} \\
(\mathrm{TR}) \\
\\
\\
\mathrm{EC} \\
(\mathrm{TR}) \\
\mathrm{EC} \\
(\mathrm{TR}) \\
\mathrm{NN} \\
(\mathrm{TR})\end{array}$ & $\begin{array}{l}{[25]} \\
{[26]} \\
{[27]}\end{array}$ \\
\hline
\end{tabular}

\section{CONSUMER APPliAnCES}

\section{A. General View}

The field of consumer or home appliances is not a popular research area in the academic community. Almost all such research activities are related to practical product development. Therefore, most of the sparse literature (mainly conference papers) on soft computing in consumer appliances has its origins in industry. Due to commercial confidentiality reasons, these conference papers do not usually give detailed descriptions of algorithms and methods used but, rather, tend to be fairly superficial. Such industrial research and development is particularly active in Japan and South Korea, while corresponding industries in Europe and the United States are only just starting to use soft computing in the control of various consumer appliances. In Japan, even ordinary consumers are aware of the great potential of fuzzy logic, neural networks, and chaos computing which have already brought machine intelligence into their daily lives. There is clearly a demand in developed countries in Asia for intelligent, human-like, and user-friendly control features. The figurative term "heartware" [30] is sometimes used in respect to such consumer products that support the following general objectives:

- comfortable way of life;

- ease of life to manage time and space;

- health- and environment-conscious life.
Although the field of research on consumer appliances differs greatly from the other application fields reviewed in this paper, an overview of state-of-the-art appliances should be given in view of the considerable and rapidly growing monetary value of the intelligent home appliance business. Besides, numerous interesting innovations have been made in this field during the past ten years.

\section{B. Application Areas}

Soft computing has been used in consumer appliances since the late 1980s [38]. In the pioneering years, fuzzy logic was clearly the dominating methodology [37]. Then, in the early 1990s, neural networks were merged with fuzzy logic to construct various neuro-fuzzy combinations; and soon after that, chaos computing (CC) started to attract interest in the Japanese appliance industry. More recently, evolutionary computation (EC) has also shown considerable potential in this heterogeneous application field. A summary of home appliances and their innovative characteristics that were made possible largely by soft computing is presented in Table 4. All of those characteristics have an obvious connection to the heartware concept mentioned above. Next, we take a closer look at three specific classes of appliances: cooling and heating, washing, and food preparation.

\section{Cooling and Heating}

The cooling and heating class of applications discussed here consists of three principal products: air conditioners, 
Table 4.

Summary of Applications of Soft Computing in Consumer Appliances

\begin{tabular}{|c|c|c|c|}
\hline Application & Characteristics & SC Component & References \\
\hline Cooling and Heating & $\begin{array}{l}\text { - Stable refrigerant distribution under chang- } \\
\text { ing loading conditions with multiple indoor } \\
\text { and outdoor units; accurate target tempera- } \\
\text { ture. } \\
\text { - Temperature, air capacity and direction of } \\
\text { air stream are determined using an estimated } \\
\text { comfortableness index; pleasant and comfort- } \\
\text { able living space. } \\
\text { - On-site learning of parameters of neural } \\
\text { network-based temperature controller; adap- } \\
\text { tation to user's habits and preferences. } \\
\text { - The number and locations of occupants are } \\
\text { identified using thermal imaging; comfortable } \\
\text { room temperature and wind direction. } \\
\text { - Stable temperature control for compensat- } \\
\text { ing heat shocks; keeps food fresh for a longer } \\
\text { period. } \\
\text { - Learns user's patterns to use the refrigerator } \\
\text { (e.g., the frequency of door openings); energy } \\
\text { savings and well-regulated temperature. } \\
\text { - Takes account the complex coupling between } \\
\text { temperature and relative humidity; favorable } \\
\text { dynamic process behavior under a wide range } \\
\text { of operating conditions. } \\
\text { - Robust disturbance handling capability; } \\
\text { comfortable and safe bathing conditions. }\end{array}$ & $\begin{array}{c}\text { FL } \\
(\mathrm{TR}) \\
\text { NN } \\
\text { (HMIQ) } \\
\text { EC, NN } \\
\text { (HMIQ) } \\
\text { FL, NN } \\
\text { (HMIQ) } \\
\text { FL, NN } \\
\text { (TR) } \\
\text { FL, NN } \\
\text { (HMIQ) } \\
\text { FL } \\
\text { (TR) } \\
\text { FL } \\
\text { (TR) }\end{array}$ & $\begin{array}{l}{[31]} \\
{[33]} \\
{[35]} \\
{[34]} \\
{[36]}\end{array}$ \\
\hline Washing & $\begin{array}{l}\text { - Fine-tuning of prediction rules; accurate es- } \\
\text { timation of dish amount. } \\
\text { - Determination of washing time using fuzzy } \\
\text { inference, and chaotic movement of a two-link } \\
\text { nozzle; lower electric power consumption and } \\
\text { higher washing efficiency. } \\
\text {-Implicit mimicking of physical sensors by neu- } \\
\text { ral network-based tuning of rough member- } \\
\text { ship functions; fine-tuned but low-cost auto- } \\
\text { matic washing machine. }\end{array}$ & $\begin{array}{l}\text { EC, FL, NN } \\
\text { (TR) } \\
\text { CC, FL } \\
\text { (HMIQ) } \\
\\
\text { FL, NN } \\
\text { (TR) }\end{array}$ & $\begin{array}{l}{[31]} \\
{[32]}\end{array}$ \\
\hline Food Preparation & $\begin{array}{l}\text {-Different phases of the heating process are } \\
\text { finely controlled according to traditional prac- } \\
\text { tices, which are reproduced; tastier cooked } \\
\text { rice. } \\
\text { - Fine-tuning of estimation rules; accurate es- } \\
\text { timation of rice amount. } \\
\text { - Fine-tuning of fuzzy control rules; optimal } \\
\text { control of the cooking process. }\end{array}$ & $\begin{array}{l}\text { FL, NN } \\
(\mathrm{TR}) \\
\\
\mathrm{EC}, \mathrm{FL}, \mathrm{NN} \\
(\mathrm{TR}) \\
\mathrm{EC}, \mathrm{FL}, \mathrm{NN} \\
(\mathrm{TR})\end{array}$ & $\begin{array}{l}{[31]} \\
{[31]}\end{array}$ \\
\hline
\end{tabular}

refrigerators, and gas heaters. These are typical products in which soft computing is now playing an important role, particularly in the Japanese market.

Nitta [30] described a new neural network-based intelligent air conditioner, in which air temperature, capacity and direction of the air stream are determined using a comfortableness index $C_{I}$, which is a function of air temperature, radiation temperature, air stream velocity, humidity, clothes worn, and metabolism. Naturally, it is not realistic to input all of those variables into a practical $C_{I}$ estimator, but a feedforward neural network can be approximating $C_{I}$ by using only the following inputs: temperature of intake air and its derivative, room temperature, air capacity, desired temperature, and direction of the air stream. In addition, an infrared image sensor is used to sense the location and number of persons, as well as the radiation temperature from different surfaces. Based on these inputs and a user-friendly, on-site training process, the approximated comfortableness index is maximized, and a more comfortable living space than that which is possible with conventional air conditioners is created. An alternative neuro-fuzzy approach to thermal imaging and detection of the location and number of persons in a room was 
proposed by Wakami et al. [33]. Their image understanding system is tailored to the needs of intelligent air conditioners.

Shim et al. discussed an application of evolutionary computation for fast and accurate on-site training of a neural network-based temperature controller in an air conditioner application [31]. They used an evolution strategy [39] for on-line tuning of the air conditioner controller, i.e., training the weights of a feedforward neural network. When such a controller is designed to follow users' habits and preferences, the undesired repetitive use of a remote controller is minimized. The most important concern is to cope with fluctuations in the operating environment. When only four remote controller operations were performed during the initial day, the neural controller was able to automatically provide a similar temperature pattern on another day when the outdoor temperature varied similarly.

Kim et al. proposed a fuzzy logic-based controller for controlling the refrigerant distribution in a multitype home air conditioner [28]. Multitype air conditioners have one outdoor unit (compressor) and multiple indoor units, and they offer the following advantages compared to more widely used single-type air conditioners: low cost, easy installment, and centralized control functions. On the other hand, it is difficult to stabilize the refrigerant distribution control when the ratio of the cooling load of indoor units to the cooling capacity of the outdoor unit is high. The refrigerant quantity is controlled by adjusting the cross-sectional area of the refrigerant pipe by a linear expansion valve. Here, $49(=7 \times 7)$ fuzzy rules are used to control the valve, and the controller has two inputs: evaporator temperature variation and goal temperature error. This fuzzy controller has a sampling rate of $0.5 \mathrm{~Hz}$ and is able to provide stable and accurate room temperature even under considerable load changes.

Refrigerators are high-volume consumer products with the following performance requirements: ability to keep the food fresh and tasty for a long time, and low energy consumption. Choi et al. introduced a fuzzy refrigerator controller that uses a complementary neural network to recognize users' behavioral pattern to use the refrigerator [34]. The goal of this intelligent controller is to maintain the inner temperature within a desired range and to provide a fully automatic operation even when the volume of food has changed remarkably. A Sugeno-type fuzzy controller is applied together with a Kohonen-type neural network, which matches the observed user pattern, i.e., inner temperature variation and frequency of door openings, to one of the categories learned from a training set. This soft computing-based controller efficiently regulates the inner temperature and compensates successfully for the volume changes in the stored food. In addition, the overall energy consumption is somewhat lower than that of conventional controllers.

Wakami et al. proposed a neuro-fuzzy controller for stable temperature regulation in a refrigerator [33]. Temperature fluctuation is normally caused by heat shocks when the door is opened, new food is put into the refrigerator, or the ambient temperature rises. Three thermal sensors inside and outside of the refrigerator are used to identify heat shock. With a straightforward neuro-fuzzy control scheme, the temper- ature rise time of existing food was reduced by $50 \%$ and the temperature restoration time was shortened by $40 \%$ compared with conventional refrigerator control. To obtain such remarkable improvements, both additional sensors and computational methods were needed. This indicates that adequate sensing, either by physical or virtual sensors, is an important part of machine intelligence.

Temperature is not the only important quantity in keeping food fresh. Relative humidity also has a considerable effect on quality and taste preservation. The rate of air circulating can also be important in certain cases. Becker et al. presented a method in which fuzzy logic enables the complex coupling of temperature and humidity to be taken into account [36]. Their fuzzy control approach gives excellent dynamic behavior under the influence of heat shock disturbances and after changes in set point values. Four inputs and two outputs are used in the controller: temperature error and its rate as well as humidity error and its rate, as the inputs to the controller; and change in refrigerator compressor power and change in evaporator fan power, as the outputs of the controller. Both the temperature and humidity control actions are based on $25(=5 \times 5)$ fuzzy rules. These two fuzzy controllers clearly outperform fixed proportional integral (PI) controllers, because the refrigeration process is highly nonlinear. It should be pointed out, however, that the improved performance is partly a result of the use of a variable-speed compressor and fan instead of conventional ON-OFF controlled actuators.

Gas heaters are commonly used in many countries, particularly in Asia, to heat water for bathing at home. In China, about one million such heater units are sold annually [29]. Conventional gas heaters have only an open-loop temperature adjustment. This leads to uncomfortable temperature fluctuations if the incoming water and gas pressures are not stable. The pressure disturbance problem may be serious in developing countries. Zhu et al. proposed an efficient low-cost gas heater with a single temperature sensor and closed-loop switched fuzzy control [29]. Soft computing-based control is an attractive alternative, since the gas heating process is both nonlinear and time-varying, thus, cannot be successfully handled with a fixed proportional integral derivative (PID) controller. The presented switched fuzzy controller offers excellent disturbance-handling characteristics compared to those of PID-type controllers. Based on the measured temperature error $T_{\text {Frror }}(t)$, the rules used for selecting the applied control principle, are given below

$$
\begin{aligned}
& \text { IF }\left|T_{\text {Error }}(t)\right| \geq T_{\text {Error-Max }} \text { THEN apply P control } \\
& \text { IF } T_{\text {Error-Min }}<\left|T_{\text {Error }}(t)\right|<T_{\text {Error-Max }} \\
& \text { THEN apply fuzzy control } \\
& \text { IF }\left|T_{\text {Error }}(t)\right| \leq T_{\text {Error-Min }} \\
& \text { THEN apply PI control with fuzzy tuning }
\end{aligned}
$$

where $T_{\text {Error-Max }}$ and $T_{\text {Error-Min }}$ are specific temperature error limits used for switching control. The $\mathrm{P}$ control phase above $T_{\text {Frror-Max }}$ is needed to provide a fast response when the error is large, the fuzzy control to ensure low overshoot, 
and the fuzzy-tuned PI control is needed to ensure accurate final temperature when the error is small. The proposed control scheme, which can be regarded as a fusion of soft computing and conventional hard computing techniques [41], ensures safe and comfortable bathing.

\section{Washing}

Washing machines and dishwashers are home appliances that can also benefit from soft computing technologies. For such applications, there are three main goals: high washing efficiency, low energy consumption, and simple user interface. Fuzzy logic, neural networks, and chaos computing are used, particularly, in Japan and South Korea to achieve these goals. In addition to the conventional goals, i.e., washing efficiency and energy consumption, the simplicity of user interface is becoming increasingly important, and soft computing is regarded as a step toward the realization of intelligent one-button operation [35].

Nomura et al. presented a dishwasher that utilizes fuzzy logic and chaos computing for reducing energy consumption and providing an efficient washing process [32]. In a conventional dishwasher, the washing time is fixed and the energy consumption is therefore unnecessarily high if there are only a few dishes. Here, fuzzy inference is used to accurately estimate the number of dishes and determine the optimal washing, rinsing, and drying times. As is widely known, a conventional water nozzle in a dishwasher is composed of one link and it makes periodic rotating movements. Consequently, the direction and area where the water is shot out are considerably limited. To solve this problem, a two-link nozzle with a complicated moving pattern is used to improve the washing efficiency. Based on time-series analyzes of nozzle movements, the behavior of the new two-link nozzle is related to deterministic chaos. The new scheme was compared to the conventional one, and it was found that the washing ratio was improved from $75 \%$ to $86 \%$. Washing ratio, $W$, is an empirical quality measure that is defined below:

$$
W=\left(T_{\text {In }}-T_{s}\right) / T_{\text {In }} * 100 \%
$$

where $T_{I n}$ is the total number of dishes in the dishwasher and $T_{s}$ is the number of washed dishes with stains (visual inspection).

Shim et al. briefly discussed a soft computing-based dishwasher control scheme [31]. In their approach a neuro-fuzzy system is used to estimate the number of dishes. Evolutionary computation is also used in this scheme for fine-tuning of the estimation rules. Since different soft computing methodologies do not compete with each other, but, rather, are complementary they are being utilized extensively in the development of advanced home appliances.

For example, a scheme in which fuzzy reasoning together with the learning ability of neural networks is used in an automatic washing machine to provide precise control of the multiphase washing process was reported by Nitta [30]. They used only three physical sensors as explicit inputs to the fuzzy reasoning unit: an optical sensor that detects the degree of soiling and type of detergents, a current sensor that detects the amount of clothes, and a water level sensor. The following additional information is also implicitly provided for the fuzzy reasoning unit: types of clothes, preferred washing course, water quality, and dissolution of detergent. This means that the membership functions of fuzzy reasoning are optimized using a neuro-fuzzy approach with only approximated initial settings. The washing and rinsing periods, number of rinsing cycles, spinning time, water level, and applied current are optimized using the proposed fuzzy system.

\section{E. Food Preparation}

Soft computing methods have also been used successfully in food preparing appliances, such as rice cookers and microwave ovens. The main goal in the design is to produce tasty food. The market for rice cookers in many Asian countries is large, but rice cookers are not used in Europe or the United States. Although rice can easily be cooked using an electric or gas rice cooker, the tastiest cooked rice is supposedly obtained only by using a traditional cooking stove, which generates intense heat. Soft computing control is used to mimic the characteristics and behavior of traditional rice cookers and experienced cooks. Nitta [30] presented the design for an intelligent rice cooker that is based on neurofuzzy reasoning. The necessary intense heat is generated by magnetic induction heating, and the expert cooking process is reproduced by neuro-fuzzy reasoning. During this sensitive multistep process, both the heating temperature and amount of water are finely controlled by rules according to given input information, e.g., preferred rice stiffness, type and amount of rice, and initial amount of water.

Shim et al. made a further step toward one-button control and true heartware by proposing a rice cooker that can estimate the amount of rice [31]. Neuro-fuzzy reasoning with evolutionary computation-based fine-tuning of estimation rules is used again in their scheme. They also proposed a microwave oven that uses similar methods for optimal control of the entire cooking or defrosting process.

\section{ELECTRIC POWER SYSTEMS}

\section{A. General View}

Neural networks were applied already in the early 1990s to electric power systems. The first conference on application of artificial neural networks to power systems was held in 1991. In the mid-1990s, fuzzy logic was applied to power system applications [58] such as control, operation, and planning. Soft computing was applied to power systems in the mid-1990s as reported in [59], which describes in detail the methods for applying SC to various power system problems. Recently, EC has been used mainly to solve control, operation, and planning problems of power systems, since power systems are typically large-scale and complex.

Data mining technology, which essentially involves searching for stable, meaningful, and easily interpretable patterns in databases using soft computing [60] has recently become popular, and this new technology may be used to 
Table 5.

Summary of Applications of Soft Computing in Electric Power Systems

\begin{tabular}{|c|c|c|c|}
\hline Application & Characteristics & SC Component & References \\
\hline Control and Monitoring & $\begin{array}{l}\text { - EC is introduced for adaptive enforcement oper- } \\
\text { ation of a power plant to shorten start-up time in } \\
\text { order to reduce fuel and electricity consumptions. } \\
\text { - A fuzzy excitation controller designed by EC is } \\
\text { applied to control of a synchronous generator. } \\
\text { - A fuzzy neural network is used for fast transient } \\
\text { stability swings prediction based on the synchro- } \\
\text { nized phasor measurements of power systems. } \\
\text { - Modified EC is introduced for simultaneous tun- } \\
\text { ing of power system damping controllers. } \\
\text { - A radial basis function neural network is utilized } \\
\text { for real-time tuning parameters of a conventional } \\
\text { power system stabilizer. } \\
\text { - An expert system using fuzzy relations is applied } \\
\text { to fault diagnosis of power systems. }\end{array}$ & $\begin{array}{c}\text { EC } \\
(\mathrm{TR}) \\
\mathrm{EC}, \mathrm{FL} \\
(\mathrm{TR}) \\
\text { FL, NN } \\
(\mathrm{TR}) \\
\mathrm{EC} \\
(\mathrm{TR}) \\
\mathrm{NN} \\
(\mathrm{TR}) \\
\text { FL } \\
\text { (HMIQ) }\end{array}$ & $\begin{array}{l}{[42]} \\
{[43]} \\
{[44]} \\
{[45]} \\
{[46]}\end{array}$ \\
\hline Operations & $\begin{array}{l}\text {-Load forecasting with neural networks is pro- } \\
\text { posed based on customers' data, which is different } \\
\text { from conventional time series data. } \\
\text { - A short-term load forecasting method for special } \\
\text { days in anomalous load conditions is developed } \\
\text { using NNs and fuzzy inference methods. } \\
\text { - Combining chaos computing with fuzzy state } \\
\text { trajectory reconstruction, daily peak electric } \\
\text { power demand forecasting is accurately achieved. } \\
\text { - A dual EC is introduced for optimizing the } \\
\text { dispatch and short-term scheduling of power re- } \\
\text { sources. } \\
\text { - Fuzzy nearest prototype classifiers are intro- } \\
\text { duced for steady state security evaluation. } \\
\text { - Solving the environmentally constrained eco- } \\
\text { nomic dispatch problems. }\end{array}$ & $\begin{array}{c}\text { NN } \\
(\mathrm{TR}) \\
\mathrm{FL}, \mathrm{NN} \\
(\mathrm{TR}) \\
\mathrm{CC}, \mathrm{FL} \\
(\mathrm{TR}, \mathrm{LC}) \\
\mathrm{EC} \\
(\mathrm{TR}) \\
\mathrm{FL} \\
(\mathrm{TR}) \\
\mathrm{EC} \\
(\mathrm{TR})\end{array}$ & $\begin{array}{l}{[48]} \\
{[49]} \\
{[73]} \\
{[51]} \\
{[52]} \\
{[53]}\end{array}$ \\
\hline Plannings & $\begin{array}{l}\text { - A price/profit-based unit commitment formula- } \\
\text { tion is provided using EC. } \\
\text { - A new approach using EC based neural networks } \\
\text { and dynamic programming is developed to solve } \\
\text { power system unit commitment problems. } \\
\text { - An improved EC is successfully applied to deal } \\
\text { with the solution of transmission network expan- } \\
\text { sion planning problem. } \\
\text { - An interactive fuzzy-norm satisfying method for } \\
\text { multi-objective reactive power sources planning is } \\
\text { presented. }\end{array}$ & $\begin{array}{l}\mathrm{EC} \\
(\mathrm{TR}) \\
\mathrm{EC}, \mathrm{NN} \\
(\mathrm{TR}) \\
\mathrm{EC} \\
(\mathrm{TR}) \\
\mathrm{FL} \\
(\mathrm{TR})\end{array}$ & $\begin{array}{l}{[54]} \\
{[55]} \\
{[56]} \\
{[57]}\end{array}$ \\
\hline
\end{tabular}

solve certain power system problems in the near future [111]. Software for data mining in a power generation station, e.g., power station performance optimization (reducing energy consumption, identifying measures to reduce operating costs) is now commercially available [61].

\section{B. Application Fields}

Since electric power systems are large-scale and complex, soft computing (especially EC) has been applied to control, diagnosis, forecasting, operation, stability assessment, dis- patching, commitment, and planning, as well as other areas of power systems. Applications of soft computing to solve power system problems in the real world are summarized in Table 5. It should be noted that power electronics technology has contributed to these intelligent power systems as the necessary hardware.

\section{Control and Monitoring}

Kamiya et al. proposed a GA with an adaptive enforcement operation that can generate and adapt enforcement 
gains during the search process for a power plant start-up scheduling. This GA enables reduction of the start-up time, resulting in reductions of fuel and utility consumption, and an increase in the capability of a power plant to adapt to changes in electricity demand [42].

Wen et al. used EC to design an optimal fuzzy logic excitation controller for an asynchronous generator. Their test results were very satisfactory. Further, they used an automated design method for fuzzy controllers [43].

A novel class of fuzzy, hyper-rectangular, composite neural networks (local-basis function neural networks) was developed by Liu et al. This method was applied to fast prediction of transient stability swings for use in high-speed control on the basis of synchronized phasor measurements. A highly successful prediction rate in real-time was obtained in simulation tests on a sample power systems [44].

Bomfirm et al. developed a method that simultaneously tuned multiple power system damping controllers using modified ECs. They suggested that human expertise will be able to be captured and readily implemented in a more elaborate fitness function [45].

Segal et al. proposed a new approach for real-time tuning of the parameters of a conventional power system stabilizer using a radial basis function neural network (RBFN). The dynamic performance of a system with an RBFN was shown to be quite robust over a wide range of loading conditions and equivalent reactances [46].

Cho et al. developed an expert system using fuzzy relations to deal with uncertainties imposed on fault diagnosis of power systems. The experimental results for real power systems showed the usefulness of their proposed technique for diagnosing faults that had considerable uncertainty [47].

\section{Operations}

Charytoniuk et al. explored an alternative approach of load forecasting based on indirect demand estimation from available customer data, instead of using time series of load changes and weather factors recorded in the past (conventional method). Neural networks were designed and trained on the basis of the aggregate demands of groups of surveyed customers in different categories [48].

Kim et al. proposed a new method for a reliable short-term load forecasting for special days in anomalous load conditions with a neuro-fuzzy approach, which had not been possible using conventional neural networks due to dissimilar load behaviors of holidays compared with those of ordinary weekdays during the year, and due to insufficient number of training patterns. In their proposed method, special days are classified into five different day-types. Five NN models for each day-type are used to forecast the scaled load curves of special days, and two fuzzy inference methods are utilized to forecast the maximum and minimum loads of those special days. Finally, the results of the both methods are combined to forecast the 24-hour load pattern of special days. Their test results showed very accurate forecasting with an average relative error of $1.78 \%$ [49].

Iokibe et al. developed a new method for short-term prediction of daily peak electric power demand. First, a nonlinear chaotic time series was considered. Then while the time series was embedded in an $n$-dimensional state space using Taken's embedding theory, the state reconstruction method by fuzzy inference was used, and the computation time was reduced remarkably due to fuzzy inference rather than neural networks. Their method was applied to accurate prediction of daily peak electric power demand [73].

MacGill et al. proposed a decentralized coordination framework for operating power systems with dispersed generation and energy storage (for optimizing the dispatch and short-term scheduling). Their method combined elements of dynamic programming with EC. Each power system resource evolved a "future benefit" function that described the impact of its own possible decisions on future power system operation. This "dual evolutionary programming" approach can handle complex resource models and objective functions [51].

Matos et al. presented a method for steady-state security evaluation using fuzzy nearest-prototype classifiers. Their method produced a global evaluation for all relevant single contingencies. Understandable natural language was used to produce standardized sentences about the security level between the system and the operator [52].

Wong et al. developed an efficient and reliable evolutionary programming-based algorithm for solving the environmentally constrained economic dispatch problem. The algorithm dealt with load demand specifications in multiple intervals of the generation scheduling horizon. The power and usefulness of the algorithm was demonstrated through its application to a test system [53].

\section{E. Planning}

Richter et al. provided an EC solution to the profit-based unit commitment algorithm. It was confirmed that EC is a useful tool in searching large discrete solution spaces; and the space of the particular solution was quite large, making EC appropriate for solving the unit commitment problem. It gave more information to users due to the flexibility of the method [54].

Huang et al. developed an approach using an EC-based neural network and dynamic programming to solve power system unit commitment problems. First, a set of feasible generator commitment schedules was formulated by EC-enhanced neural networks. Those pre-committed schedules were then optimized by the dynamic programming technique. By the proposed approach, harmful learning stagnation was avoided. The stability of the neural networks and accuracy were significantly increased. The feasibility and practicability of the proposed method were confirmed experimentally [55].

Silva et al. proposed the application of an improved GA to deal with the solution of a transmission network expansion-planning problem. Their method is better than other methods for dealing with nonconvex, nonlinear, and large mixed optimization problems. They showed that their method is a promising approach for solving such difficult problems [56]. 
Chen developed an interactive fuzzy-norm satisfying method in order to deal with fuzzy goals of the decision maker (DM) in multiobjective power sources planning problems. A satisfying solution for the DM can be obtained by updating the reference membership values based on the current values of the membership functions and objective functions. Through interaction, a global noninferior solution in each iteration is guaranteed. This fuzzy-norm approach based on the simulated annealing method was applied to solve these problems with a nonconvex objective space [57].

\section{MANUfACtURING AUTOMATION AND RoBOTICS}

\section{A. General View}

The term intelligence has been frequently used in this field since robotic technologies that mimic human thinking and behavior of bio-systems have been developed. Contemporary intelligence is sometimes considered to be interactive information processing among human beings, environment, and artificial objects [79]. Intelligence is defined as human-like information processing [77] and adaptation to environment by leaning, evolution, and prediction in order to survive [78]. The use of structured intelligence by soft computing for intelligent robots has been considered [64]. However, the interaction with human beings is also important. Recently, emotional robots that interact with human beings have attracted much interest by researchers [71]. KANSEI (emotion, feeling) information processing has become popular in Japan [70]. This technology is needed for the development of human-friendly robots. Other technologies, e.g., fuzzy associative memory and chaotic computation have also been used for developing human-friendly robots (intelligent robots, welfare robots) [68]. Soft computing is widely used in this field.

\section{B. Application Fields}

Soft computing has been used in the construction of intelligent robots and manufacturing systems and for solving nonlinear and uncertain problems in the fields of hands and manipulators, mobile robots, multiagent robots, welfare robots, emotional pet robots, and manufacturing systems. It is expected that soft computing will play an increasing role in the realization of human-friendly systems in the future.

Robots and manufacturing systems and their characteristics that have been made possible mainly by soft computing are summarized in Table 6 . These applications are discussed in more detail below.

\section{Hands and Manipulators}

Lin et al. developed compact fuzzy decentralized controllers including sensor fusion schemes and introducing human skills through communication lines for a five-finger robot hand with 17 degrees of freedom. 17 potentiometers, 18 tactile sensors, and 17 actuators were installed in the design. Digital signal processor (DSP) chips were used to implement the proposed schemes [62].
Kiguchi et al. [63] developed position/force control using the fuzzy vector method with a fuzzy neural network that received aid from an intelligent task planner. This is an intelligent control method because soft computing is used.

Fukuda et al. presented the design of an intelligent robotic system based on soft computing. An architecture of a robot system with structured intelligence was developed by them. The structured intelligence is explained such that perception and action functions are represented in the horizontal axis, and reactive motion, skilled motion, primitive motion planning, and motion planning functions as hierarchical levels are represented in the vertical axis, interacting with the environment. The role of SC is central in this intelligent robot system [64].

\section{Mobile Robots}

Baranyi et al. proposed an improved vector field-based guiding model as an extension of the potential-based guiding model. A simplified neuro-fuzzy approximation algorithm was applied to the realization of models for the guidance of mobile robots [65].

\section{E. Multiagent Robots}

Ishiguro et al. developed an architecture for behavior arbitration based on artificial immune networks. Antigens and antibodies in the artificial immune network were used as agents for environment description and decision-making for action, respectively. Each antibody (agent) was assigned by fuzzy inference (if-then, if not-then). An action decision was made following the action of the highest density agent. The complex system was optimized by EC, NN, reinforcement learning, introduction of meta knowledge and other. This was an example of the so-called reactive distributed artificial intelligence and cognitive distributed artificial intelligence. Soft computing was used in the design of reactive and cognitive artificial intelligences [66].

Katagiri et al. used fuzzy inference and random search learning, which was devised for controlling interactive behaviors of a group of multiagent robots. Less computation time was needed compared with that for other multiagent robot systems [67].

\section{F. Welfare Robots}

Kohata et al. used fuzzy associative memories and chaos computing to construct human-friendly multiagent robots for the welfare industry. Since this was a parallel computation method, the parallel processing algorithm was implemented on A-NET (Actors NETwork) [68].

Ushida et al. proposed a fuzzy-associative memory-based knowledge construction method for application to a humanmachine interface, and they demonstrated that it is an important tool for investigating human-friendly welfare robots, and a possible alternative for developing intelligent robots [69].

Takagi et al. used soft computing techniques (FL and interactive EC) for hearing impairment compensation and physical rehabilitation. In this field, the evaluation of system performance is subjective and depends on individuals (human 
Table 6.

Summary of Applications of Soft Computing in Manufacturing Automation and Robotics

\begin{tabular}{|c|c|c|c|}
\hline Application & Characteristics & SC Component & References \\
\hline $\begin{array}{c}\text { Hands and } \\
\text { Manipulators }\end{array}$ & $\begin{array}{l}\text { - A five-finger hand with 17-DOF is controlled by } \\
\text { fuzzy sensor fusion and decentralized control. } \\
\text { - A fuzzy vector method by fuzzy neural networks } \\
\text { is applied to control a manipulator for unknown ob- } \\
\text { jects. } \\
\text { - Position/force control, tracking control, and plan- } \\
\text { ning for robot manipulators are described using } \\
\text { structured intelligence by soft computing. }\end{array}$ & $\begin{array}{l}\text { FL } \\
(\mathrm{TR}) \\
\text { FL, NN } \\
(\mathrm{HMIQ}) \\
\text { EC, FL, NN } \\
(\mathrm{HMIQ})\end{array}$ & $\begin{array}{l}{[62]} \\
{[63]} \\
{[64]}\end{array}$ \\
\hline Mobile Robots & $\begin{array}{l}\text { - A vector field model is proposed in order to im- } \\
\text { prove the potential-based guiding model for mobile } \\
\text { robots. Then, a simplified neuro-fuzzy algorithm is } \\
\text { introduced to approximate them and to reduce com- } \\
\text { putational complexity. }\end{array}$ & $\begin{array}{c}\text { FL, NN } \\
(\mathrm{TR})\end{array}$ & [65] \\
\hline $\begin{array}{l}\text { Multi-Agent } \\
\text { Robots }\end{array}$ & $\begin{array}{l}\text { - Antigens and antibodies in artificial immune net- } \\
\text { works are used as multi-agents for environment rep- } \\
\text { resentation and decision making of behavior respec- } \\
\text { tively. Also, fuzzy inference and EC optimization are } \\
\text { introduced in the system. } \\
\text { - Fuzzy inference and RasID learning are introduced } \\
\text { to control of multi-agent robots. }\end{array}$ & $\begin{array}{l}\text { EC, FL, IN } \\
\text { (HMIQ) } \\
\\
\text { FL } \\
\text { (HMIQ) }\end{array}$ & {$[67]$} \\
\hline Welfare Robots & $\begin{array}{l}\text { - Fuzzy associate memories and chaotic computing } \\
\text { for memorization and recalling are proposed to con- } \\
\text { trol intelligent agents for welfare robots. } \\
\text { - Fuzzy associative memories are used to transform } \\
\text { human physical movements into qualitative linguistic } \\
\text { labels which is useful for a human-machine interface } \\
\text { of welfare robots. } \\
\text { - Interactive EC is used for hearing impairment com- } \\
\text { pensation and physical rehabilitation. }\end{array}$ & $\begin{array}{l}\text { CC, FL, NN } \\
\text { (HMIQ) } \\
\text { FL, NN } \\
\text { (HMIQ) } \\
\\
\text { EC, FL } \\
\text { (HMIQ) }\end{array}$ & $\begin{array}{l}{[68]} \\
{[69]}\end{array}$ \\
\hline $\begin{array}{c}\text { Emotional Pet } \\
\text { Robots }\end{array}$ & $\begin{array}{l}\text { - To teach a pet robot trick and dance, emotional } \\
\text { models are introduced using FL and EC for learning. } \\
\text { - Human behavior is studied using brain science. }\end{array}$ & $\begin{array}{c}\text { CC, FL } \\
\text { (HMIQ) } \\
\text { NN } \\
\text { (HMIQ) }\end{array}$ & $\begin{array}{l}{[71]} \\
{[72]}\end{array}$ \\
\hline $\begin{array}{l}\text { Manufacturing } \\
\text { Technologies }\end{array}$ & $\begin{array}{l}\text { - Failure diagnosis of rotating machine parts is car- } \\
\text { ried out using chaotic time series analysis and tra- } \\
\text { jectory reconstruction by FL. } \\
\text { - A neuro-fuzzy techniques is applied to estimate the } \\
\text { feed cutting force on tool wear based on the measured } \\
\text { motor feed current for tool wear condition monitor- } \\
\text { ing. } \\
\text { - Wavelet transformation is used to extract feature } \\
\text { by a NN classifier for vibration monitoring. } \\
\text { - Fuzzy logic controllers are implemented by recon- } \\
\text { figurable field oriented gate arrays (FPGA). }\end{array}$ & $\begin{array}{l}\text { CC, FL } \\
(\mathrm{TR}, \mathrm{LC}) \\
\text { FL, NN } \\
(\mathrm{TR}) \\
\\
\text { NN } \\
(\mathrm{TR}) \\
\text { FL } \\
\text { (TR) }\end{array}$ & $\begin{array}{l}{[75]} \\
{[76]}\end{array}$ \\
\hline
\end{tabular}

beings). KANSEI (emotion, feeling) information processing, which is popular in Japan, is suitable also for this purpose [70].

\section{G. Emotional Pet Robots}

Kubota $e t$ al. have been using an emotional model for the development of evolutional pet robots. The structured intelligence described in Sections VII-A and VII-C (perception learning and behavior learning) is based on soft computing. An emotional model based on feelings (moods) reflected by the external environment is defined for the pet robot to perform tricks through interaction with its owner. The owner teaches the pet robot how to perform tricks [71].

Atkeson et al. have been studying human behavior using humanoid robots. Interdisciplinary technologies of brain science including artificial neural networks and soft computing 
(wavelet transformation and others) have been widely used to analyze human behavior [72].

\section{H. Manufacturing Technologies}

Iokibe et al. proposed a fault diagnosis method using chaos computing for chaotic time series analysis, fuzzy reconstruction of chaos state trajectories and separation of white noise from the trajectories. Their method was applied to fault diagnosis for rotating machine parts, and it was found that the use of this method could greatly reduce the required computational time [73].

Djordjevich et al. developed a system for monitoring tool wear condition using neuro-fuzzy computing. The feed cutting force was estimated by an adaptive neuro-fuzzy inference system based on the measurement of servo motor feed currents [74].

Yen et al. proposed a wavelet-based feature extraction method for monitoring vibration conditions of dynamic systems. In their method, symptom vectors extracted by wavelet transformation were fed into the inputs of the neural network classifier [75].

Kim developed fuzzy logic controllers (FLC) using a reconfigurable field programmable gate array (FPGA) system. The FLC was partitioned into many temporally independent functional modules. Each module was installed individually on the FLC automatic design and implementation system. Each implemented module formed a downloadable hardware object that was ready to configure the FPGA chip [76].

\section{POWER Electronics AND MOTION CONTROL}

\section{A. General View}

It is well known that I/O mapping by an NN can be approximated by FL. However, an NN has advantageous knowledge acquisition capabilities by learning and more accurate mapping properties. On the other hand, FL can explain the I/O relations and is rich in knowledge representation. Besides, it is suitable for fine-tuning and representation of easily understandable knowledge expressions for human beings with less computation time. Fuzzy neural networks have therefore been applied to power electronics and motion control. In the FL approach, various kinds of clustering methods in the I/O spaces from numerical data are used and fuzzy rules are extracted adaptively [88].

In this field, systems are often nonlinear and uncertain. It is difficult to obtain rigorous mathematical models. Self-tuning (adaptive) capabilities and automated design methods are needed. Soft computing has innovatively solved such real-world problems at low cost. For hardware realization of the schemes, fast DSPs are widely available [93].

\section{B. Application Fields}

In all application fields of motion control, welding, induction motor drives, reluctance motor drives, inverters, converters, and diagnosis, there exist high nonlinearities and uncertainties such as current dependent inductance, stray inductance and capacitance, eddy current, temperature dependency effects, skin effect, friction, gear backlash, and compliance, for which rigorous mathematical models cannot be obtained. Self-tuning (adaptive, robust) capabilities and automated designs methods are needed. Soft computing $(\mathrm{FL}+\mathrm{NN})$ has innovatively solved these real-world problems [85], [86], [93]. EC is not frequently used in this field for system optimization. Since relatively fast dynamic systems are dealt with, computationally efficient fuzzy neural networks are used. Power electronics and motion control have been the basic implementation technologies for robotics and automation. Human-friendly diagnosis technology in which intelligent information processing is essential is increasingly being developed [93], [95], [96].

Table 7 presents a summary of the power electronics and motion control, and the system characteristics that have been made possible mainly by soft computing, most of which are implemented using commercially available digital signal processors. These applications are described in more detail below.

\section{Motion Control (Including Welding)}

Fahn et al. proposed a new method for estimation and control of the speed of a nonlinear servomotor. They used also EC to extract numerical control rules from the input and output data. After an evolutionary process, the resulting numerical rules constituted a lookup table. Then a fuzzy neural network was trained using the numerical data in the lookup table as teaching signals, resulting in automatic generation of fuzzy rules. The control performance using the proposed methods is superior to control performance of conventional PI controllers. An automatically designed, robust, and fastresponse control system was constructed [80].

Seidl et al. used an NN to compensate for notable gear backlash hysteresis in accurate positioning mechanisms. They analyzed the nonlinearities governing nonlinear differential equations. Then, optimal and smooth control trajectories were generated. The NN was mainly used for parameter adjustments. Accurate and robust positioning for the highly nonlinear complex system was achieved [81].

Popovic et al. developed pulse torque control, whose torque pulse shape was inferred by FL from the desired disposition data. Such a control scheme was applied to high-precision positioning. Fine-tuning was applied using experimental data. This control was particularly simple to implement and achieved high-precision positioning for highly nonlinear systems [82].

$\mathrm{Ku}$ et al. proposed a nanometric precision three-degrees-of-freedom position controller by an $\mathrm{NN}$ using the data obtained from capacitor gap sensors. First the open loop characteristics of nonlinear positioners (static stiffness, hysteresis, drift, frequency response, and coupling effects) were experimentally investigated. Then, a cerebellar model activation NN control algorithm was applied to provide real-time learning and better tracking capability than that of conventional PID control [83].

Cook et al. used two NNs for modeling and control of a variable polarity plasma arc welding process, which is highly nonlinear. The input variables to the first $\mathrm{NN}$ were the desired crown and root widths. The output variables that were the inputs to the second NN were the torch standoff, forward 
Table 7.

Summary of Applications of Soft Computing in Power Electronics and Motion Control

\begin{tabular}{|c|c|c|c|}
\hline Application & Characteristics & SC Component & References \\
\hline Motion Control & $\begin{array}{l}\text { - Speed control for a dc servomotor is designed using } \\
\text { novel EC, then implemented by a fuzzy-neural network, } \\
\text { resulting in an automatically-designed, robust (adap- } \\
\text { tive), and quick-response nonlinear system. } \\
\text { - An NN is used to identify and compensate for hys- } \\
\text { teresis caused by gear backlash, giving a fine-tuning of } \\
\text { parameters for a highly nonlinear system. } \\
\text { - The pulse torque shape is generated measuring desired } \\
\text { displacement and applying fuzzy inference in accurate } \\
\text { positioning to compensate for friction. } \\
\text { - Using a piezoelectric actuator and a capacitive gap sen- } \\
\text { sor, an NN (CMAC) is trained by experimental data to } \\
\text { generate optimal nonlinear control in accurate nonlinear } \\
\text { nanopositioning. }\end{array}$ & $\begin{array}{l}\mathrm{EC}, \mathrm{FL}, \mathrm{NN} \\
(\mathrm{TR}) \\
\\
\mathrm{NN} \\
(\mathrm{TR}) \\
\text { FL } \\
(\mathrm{TR}, \mathrm{LC}) \\
\mathrm{NN} \\
(\mathrm{TR})\end{array}$ & $\begin{array}{l}{[81]} \\
{[82]} \\
{[83]}\end{array}$ \\
\hline Welding & $\begin{array}{l}\text { - Monitoring and control for the variable polarity plasma } \\
\text { arc welding, which is a highly nonlinear system, are suc- } \\
\text { cessfully accomplished. }\end{array}$ & $\begin{array}{c}\text { NN } \\
\text { (TR) }\end{array}$ & [84] \\
\hline $\begin{array}{c}\text { Induction Motor } \\
\text { Drives }\end{array}$ & $\begin{array}{l}\text { - Using a new rotor resistance estimator, a fuzzy-neural } \\
\text { network is designed to estimate external and parame- } \\
\text { ter disturbances. Finally a robust speed controller is } \\
\text { designed. } \\
\text { - A novel torque and flux estimator is developed. Then } \\
\text { a neuro-fuzzy controller including a voltage modulator } \\
\text { is proposed resulting in a simple, robust (adaptive), and } \\
\text { nonlinear direct torque controller. } \\
\text { - For sensorless control of induction motors, a model } \\
\text { following adaptive control by a neural network is devised } \\
\text { to control speed. }\end{array}$ & $\begin{array}{c}\text { FL, NN } \\
\text { (TR) } \\
\text { FL, NN } \\
\text { ('TR) } \\
\\
\text { NN } \\
\text { (TR) }\end{array}$ & {$[86]$} \\
\hline $\begin{array}{l}\text { Switched Reluctance } \\
\text { Motor Drives }\end{array}$ & $\begin{array}{l}\text { - A classifier and adaptive fuzzy inference, which is } \\
\text { equivalent to NN functions is successfully applied to con- } \\
\text { structing an accurate position estimator. This needs less } \\
\text { computational time. }\end{array}$ & $\begin{array}{c}\text { FL } \\
(\mathrm{TR}, \mathrm{LC})\end{array}$ & [88] \\
\hline $\begin{array}{l}\text { Inverters and } \\
\text { Converters }\end{array}$ & $\begin{array}{l}\text { - A fuzzy-tuning current-vector control of a three-phase } \\
\text { PWM inverter is proposed resulting in a robust con- } \\
\text { troller. } \\
\text { - PI, sliding mode, and fuzzy controllers for power con- } \\
\text { verters are compared concluding that a fuzzy controller } \\
\text { is the most flexible and the best one. } \\
\text { - An NN is applied to a controller for the cost-effective } \\
\text { operation of a hybrid compensator for non-active power. } \\
\text { - An NN-based space vector PWM controller for a } \\
\text { voltage-fed inverter induction motor drive is proposed. }\end{array}$ & $\begin{array}{c}\text { FL } \\
(\mathrm{TR}) \\
\mathrm{FL} \\
(\mathrm{TR}) \\
\mathrm{NN} \\
(\mathrm{TR}) \\
\mathrm{NN} \\
(\mathrm{TR})\end{array}$ & $\begin{array}{l}{[89]} \\
{[90]} \\
{[91]} \\
{[92]}\end{array}$ \\
\hline Diagnosis & $\begin{array}{l}\text { - Fault diagnosis for gears using nonlinear time series } \\
\text { from an acoustic sensor is achieved by a fuzzy-neural } \\
\text { network with general parameter learning that reduces } \\
\text { remarkably the computational time. Well suitable for } \\
\text { real time operation. } \\
\text { - A fuzzy neural network is applied to motor fault detec- } \\
\text { tion (winding and bearing). The detection is accurate } \\
\text { (100\%). Unnecessary rules are eliminated by learning. } \\
\text { - A fuzzy-neuro classifier is applied to detection of vari- } \\
\text { ous kinds of motor faults. Intelligent information tech- } \\
\text { nologies are applied to diagnosis. It is accurate, robust, } \\
\text { and human-friendly. }\end{array}$ & $\begin{array}{c}\text { FL, NN } \\
(\mathrm{TR}, \mathrm{LC}) \\
\\
\text { FL, NN } \\
(\mathrm{TR}) \\
\text { NN } \\
\text { (HMIQ) }\end{array}$ & [96] \\
\hline
\end{tabular}

current, reverse current, and travel speed. The final output variables were the resulting crown width and resulting root width, which were used for the actual welding. Each NN was trained using experimental data [84].

\section{Induction Motor and Switched Reluctance Motor Drives}

Lin et al. identified the temperature-dependent rotor resistance by a model following adaptive controller to realize a 
decoupled stator-flux-oriented induction motor drive. Then, a combined external and parameter disturbance observer was constructed using an NN. The estimated disturbance was forwarded to the input in parallel with an IP controller, resulting in a robust nonlinear controller. The $\mathrm{NN}$ was trained using experimental data [85].

Grabowski et al. developed a new flux and torque estimator for nonlinear decoupling. They used an adaptive neuro-fuzzy inference system for constructing a controller and voltage modulator based on estimates of flux and torque. It was experimentally shown that this simple controller gave fast torque and flux responses, satisfactory operation even at very low speeds, and simple tuning capability [86].

Sensorless speed control is greatly emergent. Ben-Brahim et al. introduced a neural network to model adaptive speed control. Accurate speed control at a relatively low speed was achieved [87].

Cheok et al. extracted fuzzy rules by clustering experimental data and constructed a fuzzy adaptive position estimator of a switched reluctance motor drive. Their proposed method has the following advantages [88]:

- no mathematical model is required;

- no requirement for large lookup tables; and

- fuzzy models allow fast computation.

\section{E. Inverters and Converters}

Tzou et al. developed a fuzzy tuning PID current controller generating quasi-optimal PWM patterns for a three-phase pulse width modulation (PWM) inverter. The controller is simple and robust, and provides for fast transient response and low total harmonic distortion [89].

Raviraj et al. concluded on the basis of the experimental results that a fuzzy controller is the most flexible and best among a sliding mode controller, PI controller, and fuzzy controller for power converters [90].

Pretorius et al. used a neural network controller that chose the most cost-effective compensator mode of operation on the basis of continuous analysis of load conditions and operational losses of the elements in the compensator structure. This controller saved $30 \%-70 \%$ operational losses compared with a conventionally controlled hybrid compensator [91].

Pinto et al. implemented a neural-network-based spacevector PWM modulation of a voltage-fed inverter. It covers the under-modulation and over-modulation regions linearly extending operation smoothly up to square wave [92].

\section{F. Diagnosis}

Akhmetov et al. developed a fuzzy neural network with general parameter learning for diagnosis of automobile transmission gears using a measured nonlinear time series from an acoustic sensor. It is an automatically designed, self-organizing, and adaptive fault detector that remarkably reduced the computation time in real time operation [93].

Shaikh et al. presented a fault diagnosis scheme for nonlinear time series using linear regression method and finite impulse response (FIR) neural network. They detected the fault using regression lines obtained from raw normal and abnormal data. FIR network was then used to estimate the unknown system for the normal condition data and to filter the abnormal condition data. The existence of a fault was then confirmed using regression lines plotted for the predicted normal and filtered abnormal data. The scheme was successfully applied to two real-world problems using acoustic and vibration data recorded from rotating parts of an automobile and a boring tool, respectively. The scheme provided good results [94].

Goode et al. proposed an NN/FL system for incipient fault diagnosis in induction motors. Their system that was connected in series for the extraction of membership functions and fuzzy rules, was trained by modified learning algorithms using experimental data. It achieved $100 \%$ detection accuracy [95].

Fussel et al. developed a fuzzy neural network classifier for use in a multifault detection system for a dc motor. Structure knowledge and experimental data were used for a decision tree. As a conclusion, soft computing methods will be increasingly applied to challenging diagnosis problems, leading to human friendly motor drive systems [96].

\section{Process EngINEERING}

\section{A. General View}

Fuzzy logic was first used in the process industry in Japan in 1987. Since processes are usually nonlinear, uncertain and complex, highly skilled operators have controlled process plants. Fuzzy control was devised to mimic skilled operator's control. In the U.S., neural networks were applied to the chemical process industry in the late 1980s. Since the chemical industry has typically a lot of operation data available, neural networks are suitable for nonlinear time series analysis. Soft computing offers additional adaptation capability to solve nonlinear and uncertain process engineering problems. Since these processes are large-scale and complex, data mining technology, which has been developed since the late 1980 s using heterogeneous methodologies, including soft computing methods based on pattern recognition technology, has recently been used for interpreting and understanding important associations hidden in large process databases [104]. Due to commercial confidentiality reasons, people working in process industries do not usually publish detailed technical papers; their work is focused on the development of practical products. However, data mining software for process industry is now commercially available [111]. Data mining provides the understanding of process and plant performance and, therefore, builds a solid basis for remarkable degree of cost savings and profitability. Data mining technology is being used in the following demanding areas [112]:

- load forecasting and operation guidance for air conditioning systems;

- monitoring of the performance of heating systems;

- inner state estimation for stills (soft sensing);

- quality modeling and quality improvement operation guidance for dissolution processes;

- virtual sensors for the paper industry; 
- virtual sensors for a furnace;

- oil ingredient prediction;

- final quality prediction for chemical reactor process; and

- evaluation of drug effects.

\section{B. Application Fields}

The processes in the chemical, paper, and steel industries are all highly nonlinear and uncertain. Also, process systems are usually large-scale and complex. Therefore, data mining technology using soft computing is attractive for the operation of process plants.

Table 8 presents a summary of process industry applications and their innovative characteristics that have been made possible largely by soft computing. These application fields are discussed in detail below.

\section{Chemical Process Industry}

McAvoy surveyed various kinds of neural networks applied to chemical processes for diagnosis, modeling, feedforward control, soft sensing, and nonlinear model prediction control to optimize plant operation. These NN systems created considerable economic benefits utilizing a lot of process data [97].

Koivo discussed different kinds of neural networks and showed that a multilayer perceptron, a radial basis function neural network, and Kohonen feature maps have been innovatively applied to static and dynamic fault diagnosis and to the control of industrial processes, and have been very profitable for the process industry [98].

Maki et al. proposed a two-stage neural network as the basic structure of a fault detection system. The first stage of the network detected the dynamic trend of each measurement, and the second stage diagnosed the fault. Their system was experimentally applied to fault detection and diagnosis of a well-stirred tank reactor and it showed satisfactory performance [99].

Lu et al. developed a fuzzy expert optimization control system for a fluidized catalytic cracking unit (FCCU) in an oil refinery to optimize the cracking product distribution under a variable production environment. First, an adaptive fuzzy relational model with self-learning and prediction control that could interact with a skilled human operator was devised. Then, the structure of fuzzy reasoning was constructed as a total fuzzy expert system. It was successfully tested in a large-scale FCCU and the results showed significant benefits through fuzzy optimization control [100].

Iwasa et al. devised a self-tuning PID valve controller with a neural network for temperature control of a nonlinear and complex batch reactor, which produced polyethylene. The neural network was trained to mimic an experienced operator. The results of experiments showed that the proposed scheme was able to improve the control performance efficiently [101].

Schenker et al. proposed a reliable long-range predictive controller that consisted of two neural networks with an external feedback. The networks used an external feedback of the process state, yielding a state-space mapping that eliminated the drawbacks of I/O mapping of the feedforward networks. Their controller was experimentally applied to a semibatch chemical reactor. The results showed the feasibility of using neural networks as intelligent sensors and as longrange dynamic predictors [102].

Sbarbaro et al. devised three-level hierarchical control using three radial basis function neural networks (RBFN) for a large-scale process. A valve controller was designed for the lowest level. On the middle level, a real time adaptive nonlinear controller for a water and air tank was proposed. On the highest level, a supervisory PID controller was devised. The RBFN required only little computation time and was shown to be suitable for efficient real-time operation [103].

Kewley et al. proposed data strip mining with neural networks for the virtual design of pharmaceuticals. Their method enabled extraction of predictive models from data sets that had a large number of potential inputs and comparatively few data points. The methodology used neural network sensitivity analysis to determine which predictors were the most significant in the particular problem. Elimination of variables through neural network sensitivity analysis and prediction of performance through model cross-validation allowed the analyst to reduce the number of inputs and improve the predictive ability at the same time [104].

\section{Paper Process Industry}

Scharcanski et al. devised a simulator (model) for a paper forming process using a neural network. The new model yielded data corresponding to data obtainable along arbitrary scanning lines in planar stochastic fibrous structures, providing profiles, variances, histograms of local area density, and histograms of local free-fiber lengths. These results closely resembled experimental data from commercial paper samples obtained from radiographic or optical transmission images subjected to image analysis [105].

Viljamaa et al. proposed a fuzzy system to compute new target values for low-level controllers during grade changes in a paper machine. The system was designed and tuned in cooperation with human operators of the paper machine. The design method utilized both heuristic knowledge and estimation techniques based on I/O data. The obtained knowledge during design and tuning were preserved also during optimization of the fuzzy model [106].

\section{E. Steel Process Industry}

Kayama et al. devised a sensor fault detection scheme for a complex, large-scale feedback system using immune networks, Kohonen's feature maps, and fuzzy inference. The sensors were antibodies connected to each other. Each sensor watched another sensor's output and informed its abnormality by fuzzy decision making from learning vector quantizations from other sensors. This method was applied to sensor failure detection of a large scale and complex furnace in steel industry [107].

Block et al. proposed hierarchical control for a steel plant. The control objectives were mainly reached by incorporating 
Table 8.

Summary of Applications of Soft Computing in Process Engineering

\begin{tabular}{|c|c|c|c|}
\hline Application & Characteristics & SC Component & References \\
\hline $\begin{array}{l}\text { Chemical Process } \\
\text { Industry }\end{array}$ & $\begin{array}{l}\text { - An NN is applied to nonlinear time series (plant } \\
\text { data) analysis in control, diagnosis, and operation } \\
\text { guidance to increase the profit in chemical industry. } \\
\text { - Various kinds of neural networks are applied to } \\
\text { static and dynamic fault diagnosis and control for } \\
\text { process industry including chemical industry. } \\
\text { - Two neural networks are used for transient and } \\
\text { static fault diagnosis, respectively, for a well-stirred } \\
\text { tank reactor. } \\
\text { - Fuzzy optimal control is applied to a fluidized cat- } \\
\text { alytic cracking unit in an oil refinery to optimize the } \\
\text { cracking product distribution under a variable pro- } \\
\text { duction environment. } \\
\text { - An NN is used to tune PID gains for temperature } \\
\text { control of a batch reactor. } \\
\text { - Two neural networks are connected in series in the } \\
\text { feedback path to realize model predictive control for } \\
\text { a chemical reactor. This is a state feedback control } \\
\text { that is more robust and easily implemented since it } \\
\text { is based on plant knowledge rather than an input- } \\
\text { output model. } \\
\text { - Three radial basis function neural networks are used } \\
\text { to construct a hierarchical (three-level) controller for } \\
\text { chemical process. } \\
\text { - Data mining technology is applied to the virtual } \\
\text { design of pharmaceuticals using sensitivity analysis } \\
\text { of a neural network. }\end{array}$ & $\begin{array}{c}\text { NN } \\
(\mathrm{TR}) \\
\text { NN } \\
(\mathrm{TR}) \\
\mathrm{NN} \\
(\mathrm{TR}) \\
\mathrm{FL} \\
(\mathrm{TR}, \mathrm{LC}) \\
\\
\mathrm{NN} \\
(\mathrm{TR}) \\
\mathrm{NN} \\
(\mathrm{TR}) \\
\\
\\
\mathrm{NN} \\
(\mathrm{TR}) \\
\mathrm{NN} \\
(\mathrm{HMIQ})\end{array}$ & $\begin{array}{l}{[98]} \\
{[99]} \\
{[100]}\end{array}$ \\
\hline $\begin{array}{l}\text { Paper Process } \\
\text { Industry }\end{array}$ & $\begin{array}{l}\text { - Paper-forming dynamic process, which is complex } \\
\text { and nonlinear, is modeled using an NN. The analysis } \\
\text { results resemble closely the experimental results from } \\
\text { the combination of conventional methods. } \\
\text { - A fuzzy system is proposed to compute new target } \\
\text { values for low-level controllers during grade changes } \\
\text { in paper machine. }\end{array}$ & $\begin{array}{c}\text { NN } \\
(\mathrm{TR}) \\
\\
\mathrm{NN} \\
(\mathrm{TR}, \mathrm{LC})\end{array}$ & [105] \\
\hline $\begin{array}{l}\text { Steel Process } \\
\text { Industry }\end{array}$ & $\begin{array}{l}\text { - An immune network, Kohonen's neural network, } \\
\text { and fuzzy inference are used for sensor failure detec- } \\
\text { tion in the complex feedback loops for the furnace of } \\
\text { steel industry. } \\
\text { - A hierarchical controller is proposed for a large- } \\
\text { scale complex production process in a steel plant at } \\
\text { a hot dip galvanizing line. The highest level incorpo- } \\
\text { rates the skills of the operators in neural networks. } \\
\text { In the middle and lower levels, the optimal ther- } \\
\text { mal cycle of alloying is determined using an RBFN. } \\
\text { For learning algorithms, the fuzzy C-means are used } \\
\text { based on the obtained data. An NN is used for con- } \\
\text { trol of the furnace. } \\
\text { - A real-time fuzzy-based diagnosis method for the } \\
\text { influence of roll eccentricity on the strip thickness at } \\
\text { the exit of a finishing hot strip mill. } \\
\text { - A fuzzy self-tuning PID controller using operator's } \\
\text { knowledge for continuous casting mold level control } \\
\text { is proposed. }\end{array}$ & $\begin{array}{l}\text { FL, IN, NN } \\
(\mathrm{TR}) \\
\text { FL, NN } \\
\text { (TR) }\end{array}$ & $\begin{array}{l}{[109]} \\
{[110]}\end{array}$ \\
\hline
\end{tabular}

the skills of operators in neural models, at different levels of control. Low-level supervision of measurement and operating conditions was obtained. The optimal thermal cycle of alloying was determined using an RBFN and a static data- base was built up from recorded measurements. The learning of the weights was carried out from the results of a fuzzy $\mathrm{C}$-means clustering algorithm. Control of the annealing furnace was achieved by mixing a static inverse model of the 
Table 9.

Summary of Applications of Soft Computing in Transportation

\begin{tabular}{|c|c|c|c|}
\hline Application & Characteristics & SC Component & References \\
\hline Building Transportation & $\begin{array}{l}\text { - A hall call assignment method based on the fuzzy } \\
\text { theory and the fuzzy elevator group control system is } \\
\text { proposed. Efficient handling of different traffic pro- } \\
\text { files and intensities. } \\
\text { - A combination of floor-attribute-based evaluation } \\
\text { and car-attribute-based evaluation is used for eleva- } \\
\text { tor group control. Genetic algorithms are used for a } \\
\text { parameter tuning method. Improved service quality } \\
\text { of a few preferential floors without causing consider- } \\
\text { able disturbances to normal floors. }\end{array}$ & $\begin{array}{c}\text { FL } \\
(\mathrm{TR}, \mathrm{LC}) \\
\mathrm{EC} \\
(\mathrm{TR})\end{array}$ & [113] \\
\hline Road Transportation & $\begin{array}{l}\text { - Traffic-actuated fuzzy logic signal group control is } \\
\text { proposed, which gives better performance than other } \\
\text { methods. Coordinated traffic control of multiple in- } \\
\text { tersections with one-way streets. } \\
\text { - Based on a training of a fuzzy-neural network on } \\
\text { the car driver's choice, the route selection function } \\
\text { can be made adaptive to the decision making of the } \\
\text { driver. } \\
\text { - A genetic algorithm-based fuzzy PI/PD controller } \\
\text { is proposed for an automotive active suspension sys- } \\
\text { tem. } \\
\text { - Neuro fuzzy approaches, which are promising meth- } \\
\text { ods to interface between a vehicle operator and a car, } \\
\text { are used for transmission control with variable loads. } \\
\text { - To improve the speed control performance of an } \\
\text { electric vehicle system, a PID type neuro-controller } \\
\text { is proposed. } \\
\text { - A fast fuzzy neural network, called LOLIMOTO } \\
\text { (Local Linear Model Tree) is used for vehicle dy- } \\
\text { namic simulation, diagnosis, and control. }\end{array}$ & $\begin{array}{l}\text { FL } \\
(\mathrm{TR}) \\
\\
\text { FL, NN } \\
\text { (HMIQ) } \\
\text { EC, FL } \\
\text { (TR) } \\
\text { FL, NN } \\
(\mathrm{HMIQ}) \\
\text { NN } \\
\text { (TR) } \\
\text { FL, NN } \\
\text { (TR) }\end{array}$ & $\begin{array}{l}{[117]} \\
{[118]} \\
{[119]} \\
{[120]}\end{array}$ \\
\hline Rail Transportation & $\begin{array}{l}\text { - A genetic algorithm is proposed to optimize train } \\
\text { movements using appropriate coast control that } \\
\text { can be integrated within automatic train operation } \\
\text { (ATO) systems. Efficient optimization of coast con- } \\
\text { trol strategies; improved punctuality, ride comfort, } \\
\text { and energy consumption. } \\
\text { - A fuzzy-knowledge based neural network system is } \\
\text { developed and is applied to the maintenance of ticket } \\
\text { machines. }\end{array}$ & $\begin{array}{c}\text { EC } \\
(\mathrm{TR}) \\
\\
\text { FL, NN } \\
(\mathrm{HMIQ})\end{array}$ & [122] \\
\hline
\end{tabular}

furnace based on a multilayer perceptron. The neural network was then pruned in order to enhance the generalization capabilities [108].

Garcia et al. developed a real-time FL-based diagnosis system of roll eccentricity influence on the strip thickness at the exit of a finishing hot strip mill. Implementation of this system resulted in production cost reductions. Fuzzy logic was used to compare spectra and searching for common patterns, which allowed for a totally automated diagnosis system. A least-squares algorithm was used for accurate estimation of roll eccentricity [109].

Dussud et al. devised a fuzzy controller using the available expert knowledge for controlling the casting mold level during disturbed phases. This controller was integrated with a PID controller resulting in a global control architecture. It was experimentally shown to be satisfactory [110].

\section{TRANSPORTATION}

\section{A. General View}

Transportation is a large field with diverse and challenging problems to solve. Since the field of transportation mostly serves ordinary people, passengers, human-orientation and safety in various controls, fault diagnosis, and logistics operations are of considerable importance. It can be seen from Table 1 that nearly 12\% of all published conference and journal papers in the field of Transportation contain applications of soft computing. Based on this considerable proportion, it can be concluded that soft computing forms an important collection of methodologies in transportation research and development. On the other hand, less than $4 \%$ of all soft computing papers are related to transportation. These two proportions have remained fairly constant during 
the five-year period of 1995-1999. Thus, the use of soft computing has already a mature position in the field of transportation.

Since the early 1990s soft computing has attracted intelligent automobile researchers. Soft computing is widely used in this field since ground transportation systems are human related, and also nonlinear and uncertain. Intelligent vehicle control requires the following functions:

- recognition of the driving environment;

- planning of driving based on the recognized environment; and

- planning of driving that is easily acceptable for drivers.

\section{B. Application Fields}

Elevators should be comfortable for passengers and their group dispatching control is complex. FL and EC are therefore often used in state-of-the-art elevator control systems. Soft computing is an efficient means for constructing intelligent vehicles, since the machine, driver, and the driving environment are interacting with each other. Train operation requires comfort and safe for passengers and the operation scheduling is complex. Therefore, soft computing has shown to be effective in transportation applications. Table 9 presents a summary of the applications of soft computing in this field. The applications and their characteristics are described in detail below.

\section{Building Transportation}

Kim et al. designed an FL-based elevator group control system. In the control strategy generation part, the passenger traffic patterns for elevator operation were classified, and membership functions, used at the hall call assignment, were created using both the classified traffic mode and degrees of importance of the evaluation criteria. In the hall call assignment part, the suitabilities of individual elevator cars for each registered hall call were given by fuzzy inference and by rank of the overall suitability [113].

Fujino et al. proposed both floor-attribute-based and car-attribute-based evaluations. Genetic algorithms were used for parameter optimization that improved considerably the critical transportation capacity under demanding traffic conditions [114].

\section{Road Transportation}

Traffic-actuated fuzzy logic signal group control was developed by Niittymaki et al. It was shown that the proposed method was more efficient than other traffic signal control algorithms [115].

Pang et al. presented a route selection algorithm based on a driver's preference. A fuzzy-neuro approach was used to represent the correlation of the attributes with the driver's route selection. Based on training of the fuzzy neural network for the driver's actual selections, the route selection function could be made adaptive to the decision-making of the driver [116].

Kuo et al. developed a genetic algorithm-based fuzzy PI/PD controller for an automotive active suspension system.
The results of real-time simulation demonstrated that the proposed method could provide passengers with a much more comfortable ride [117].

Hayashi et al. developed neuro-fuzzy transmission control for an automobile with variable loads. In their control method, vehicle loads and the driver's intention were estimated by fuzzy inference, and optimal gear-shift moment selection was achieved by a neural network. Comfortable driving with variable loads was achieved [118].

Matsumura et al. proposed an online self-tuning PID controller for speed control of an electric vehicle using a neural network. Their controller enabled both the drivers and passengers to have a comfortable ride [119].

Holtsmann et al. developed a fast fuzzy neural network, which realized Sugeno's type-I fuzzy system. It was applied to control, diagnosis, and simulation of vehicles. This fast fuzzy neural network is able to replace the traditionally used look-up tables [120].

\section{E. Rail Transportation}

Chang et al. proposed a dynamic train coast controller. A genetic algorithm-based method was developed for synthesizing the train coast look-up table before departing from each station for an interstation run. Both indices of punctuality and riding comfort were incorporated successfully into the fitness function in the form of a penalty factor [121].

Liu et al. developed a fuzzy neural network and examined its performance. It was successfully applied to the maintenance of ticket machines. The model utilized specific knowledge of experts that was transformed into fuzzy membership functions through certain control rules. Conventional analytical methods were not able to give satisfactory solutions in this case [122].

\section{Future OpPORTUNITIES}

The successful applications of soft computing (SC) suggest that SC will have increasingly greater impact in the coming years. Soft computing is already playing an important role both in science and engineering.

In many ways, soft computing represents a significant paradigm shift (breakthrough) in the aim of computing, a shift that reflects the fact that the human mind, unlike state-of-the-art computers, possesses a remarkable ability to store and process information, which is pervasively imprecise, uncertain, and lacking in categoricity [2].

Soft computing can be extended to include computing not only from human thinking aspects (mind and brain) but also from bio-informatic aspects [78]. In other words, cognitive and reactive distributed artificial intelligence will be developed and applied to large-scale and complex industrial systems.

In fuzzy systems, computation with words will be investigated increasingly [77] and also evolutionary computation will be emerging [78]. It is expected that they will be applied to the construction of more advanced intelligent industrial systems. 


\section{CONClusion}

Soft computing is already a major area of academic research. However, the concept is still evolving, and new methodologies, e.g., chaos computing and immune networks are nowadays considered to belong to SC. While this methodological evolution is taking place, the number of successful soft computing-based products is increasing concurrently. In the majority of such products, SC is hidden inside systems or subsystems, and the end user does not necessarily know that soft computing methods are used in control, diagnosis, pattern recognition, signal processing, etc. This is the case when SC is mainly used for improving the performance of conventional hard computing algorithms or even replacing them. However, soft computing is very effective when it is applied to real-world problems that are not able to be solved by traditional hard computing. Another class of products uses soft computing for implementing novel intelligent and user-friendly features. Soft computing enables industrial systems to be innovative due to the important characteristics of soft computing: tractability (TR), high machine intelligence quotient (HMIQ), and low cost (LC).

\section{REFERENCES}

[1] P. J. Werbos, "Neuro-control and elastic fuzzy logic: Capabilities, concepts, and applications," IEEE Trans. Ind. Electron., vol. 40, pp. 170-180, Apr. 1993.

[2] Y. Dote and R. G. Hoft, Intelligent Control-Power Electronics Systems. Oxford, U.K.: Oxford Univ. Press, 1998.

[3] L. A. Zadeh, "Fuzzy logic, neural networks and soft computing," in Proc. IEEE Int. Workshop Neuro Fuzzy Control, Muroran, Japan, 1993, p. 1.

[4] _ - "The role of soft computing and fuzzy logic in the conception, design, and development of intelligent systems," in Proc. IEEE Int. Workshop Soft Computing in Industry, Muroran, Japan, 1996, pp. 136-137.

[5] — - "From computing with numbers to computing with words-From manipulation of measurements to manipulation of perceptions," in Proc. IEEE Int. Workshop Soft Computing in Industry, Muroran, Japan, 1999, pp. 221-222.

[6] L. X. Wang, "Fuzzy systems are universal approximators," in Proc. IEEE Int. Conf. Fuzzy Systems, San Francisco, CA, 1992, pp. $1163-1172$.

[7] S. Sato, Y. Arai, and K. Hirota, "Pattern recognition using fuzzy inference with lacked input data," in Proc. IEEE Int. Conf. Fuzzy Systems, San Antonio, TX, 2000, pp. 100-104.

[8] J.-S. R. Jang and C.-T. Sun, "Functional equivalence between radial basis function networks and fuzzy inference systems," IEEE Trans. Neural Networks, vol. 4, pp. 156-159, Jan. 1993.

[9] R. Shorten, R. Murray-Smith, R. Bjorgan, and H. Gollee, "On the interpretation of models in blended multiple model structures," Int. J. Control, vol. 72, no. 7/8, pp. 620-628, 1999.

[10] T. F. Junge and H. Unbehauen, "On-line identification of nonlinear systems using structurally adaptive rectangular local linear model networks," in Proc. 3rd SIMONET Workshop Recent Results in System Identification and Modeling, Bochum, Germany, 1997, pp. $1-7$.

[11] O. Nelles, "Orthogonal basis functions for nonlinear system identification with local linear model trees (LOLIMOTO)," in Proc. 11th IFAC Symp. System Identification, Fukuoka, Japan, 1997, pp. 667-672.

[12] R. Murray-Smith and T. A. Johansen, Eds., Multiple Model Approaches to Modeling and Control. London, U.K.: Taylor \& Francis, 1997.
[13] C.-H. Lee and C.-H. Teng, "Identification and control of dynamic systems using recurrent fuzzy neural networks," IEEE Trans. Fuzzy Syst., vol. 8, pp. 349-366, Aug. 2000.

[14] P. A. Marchi, L. S. Coelho, and A. A. R. Coelho, "Comparative study of parametric and structural methodologies in identification of an experimental nonlinear process," in Proc. IEEE Int. Conf. Control Applications, Kohala Coast, HI, 1999, pp. 1062-1067.

[15] A. J. Calise, "Neural networks in nonlinear aircraft flight control," IEEE Aerosp. Electron. Syst. Mag., vol. 11, no. 7, pp. 5-10, 1996.

[16] M. R. Napolitano, J. L. Casanova, D. A. Windon, II, B. Seanor, and D. Martinelli, "Neural and fuzzy reconstructors for the virtual flight data recorder," IEEE Trans. Aerosp. Electron. Syst., vol. 35, no. 1, pp. 61-71, 1999.

[17] N. L. Schneider, S. Narayanan, and C. Patel, "Integrating genetic algorithms and interactive simulations for airbase logistics planning," in Soft Computing in Industrial Applications, Y. Suzuki, S. Ovaska, T. Furuhashi, R. Roy, and Y. Dote, Eds. London, U.K.: SpringerVerlag, 2000, pp. 309-317.

[18] H. R. Berenji, "Computational intelligence and soft computing for space applications," IEEE Aerosp. Electron. Syst. Mag., vol. 11, no. 8, pp. 8-10, 1996.

[19] A. Martin-Alvarez, R. Volpe, S. Hayati, and R. Petras, "Fuzzy reactive piloting for continuous driving of long range autonomous planetary micro-rovers," in Proc. IEEE Aerospace Conf., vol. 2, Aspen, CO, 1999, pp. 127-135.

[20] G. Kolumban, M. P. Kennedy, and L. O. Chua, "The role of synchronization in digital communications using chaos-Part I: Fundamentals of digital communications," IEEE Trans. Circuits Syst. I, vol. 44, pp. 927-936, Oct. 1997.

[21] S. K. Patra and B. Mulgrew, "Fuzzy implementation of a Bayesian equaliser in the presence of inter-symbol and co-channel interference," Inst. Elect. Eng. Proc. Commun., vol. 145, no. 5, pp. 323-330, 1998.

[22] C. E. Cramer and E. Gelenbe, "Video quality and traffic QoS in learning-based sub-sampled and receiver-interpolated video sequences," IEEE J. Select. Areas Commun., vol. 18, pp. 150-167, Feb. 2000

[23] J. M. Jou and P.-Y. Chen, "A fast and efficient lossless data-compression method," IEEE Trans. Commun., vol. 47, pp. 1278-1283, Sept. 1999.

[24] E. Gelenbe, I. W. Habib, S. Palazzo, and C. Douligeris, "Guest editorial: Intelligent techniques in high speed networks," IEEE J. Select. Areas Commun., vol. 18, pp. 145-149, Feb. 2000.

[25] G. Chakraborty and B. Chakraborty, "A genetic algorithm approach to solve channel assignment problem in cellular radio networks," in Proc. IEEE Midnight-Sun Workshop Soft Computing Methods in Industrial Applications, Kuusamo, Finland, 1999, pp. 34-39.

[26] B. Dengiz, F. Altiparmak, and A. E. Smith, "Local search genetic algorithm for optimal design of reliable networks," IEEE Trans. Evol. Comput., vol. 1, pp. 179-188, June 1997.

[27] X. M. Gao, X. Z. Gao, J. M. A. Tanskanen, and S. J. Ovaska, "Power prediction in mobile communication systems using an optimal neural-network structure," IEEE Trans. Neural Networks, vol. 8, pp. 1446-1455, Nov. 1997.

[28] J. H. Kim, K. S. Kim, M. S. Sim, K. H. Han, and B. S. Ko, “An application of fuzzy logic to control the refrigerant distribution for the multi type air conditioner," in Proc. IEEE Int. Fuzzy Systems Conf., vol. 3, Seoul, Korea, 1999, pp. 1350-1354.

[29] R. Zhu, B. Tian, Q. Wang, and G. Dai, "Application of fuzzy logic in home appliance: Gas heater controller design," in Proc. IEEE Int. Conf. Intelligent Processing Systems, Beijing, China, 1997, pp. 373-376.

[30] T. Nitta, "Applications of neural networks to home appliances," in Proc. IEEE Int. Joint Conf. Neural Networks, Nagoya, Japan, 1993, pp. 1056-1060.

[31] M. Shim, S. Seong, B. Ko, and M. So, "Application of evolutionary computations at LG Electronics," in Proc. IEEE Int. Fuzzy Systems Conf., vol. 3, Seoul, Korea, 1999, pp. 1802-1806.

[32] H. Nomura, N. Wakami, and S. Kondo, "Non-linear technologies in a dishwasher," in Proc. Int. Joint Conf. 4th IEEE Int. Conf. Fuzzy Systems and the 2nd Int. Fuzzy Engineering Symp., Yokohama, Japan, 1995, pp. 57-58.

[33] N. Wakami, S. Araki, and H. Nomura, "Recent applications of fuzzy logic to home appliances," in Proc. IEEE Int. Conf. Industrial Electronics, Control, and Instrumentation, Maui, HI, 1993, pp. 155-160. 
[34] B.-J. Choi, S.-W. Han, and S.-K. Hong, "Refrigerator temperature control using fuzzy logic and neural network," in Proc. IEEE Int. Symp. Industrial Electronics, Pretoria, South Africa, 1998, pp. 186-191.

[35] N. Wakami, K. Mizutani, M. Kataoka, and T. Imanaka, "Fuzzy intelligent information processing in home appliances," in Proc. IEEE Int. Conf. Knowledge-Based Intelligent Systems, Adelaide, Australia, 1997, pp. 181-185.

[36] M. Becker, D. Oestreich, H. Hasse, and L. Litz, "Fuzzy control for temperature and humidity in refrigerator systems," in Proc. 3rd IEEE Conf. on Control Applications, Glasgow, Scotland, 1994, pp. 1607-1612.

[37] S. Dutta, "Fuzzy logic applications: Technological and strategic issues," IEEE Trans. Eng. Manage., vol. 40, no. 3, pp. 237-254, 1993.

[38] K. Hirota, "History and recent trends in soft computing research and application aspects in Japan," in Proc. IEEE Int. Conf. Intelligent Engineering Systems, Yokohama, Japan, 1997, pp. 31-37.

[39] T. Bäck, Evolutionary Algorithms in Theory and Practice. New York: Oxford Univ. Press, 1996, pp. 66-91.

[40] H. Takagi, "R\&D in intelligent technologies: Fusion of NN, FL, GA, chaos, and human," in Half-Day Tutorial/Workshop, IEEE Int. Conf. Systems, Man, and Cybernetics, Orlando, FL, 1997.

[41] S. J. Ovaska, Y. Dote, T. Furuhashi, A. Kamiya, and H. F. VanLandingham, "Fusion of soft computing and hard computing techniques: A review of applications," in Proc. IEEE Int. Conf. Systems, Man, and Cybernetics, Tokyo, Japan, 1999, pp. 370-375.

[42] A. Kamiya, K. Kawai, I. Ono, and S. Kobayashi, "Adaptive-edge search for power plant start-up scheduling," IEEE Trans. Syst., Man, Cybern. C, vol. 29, pp. 518-530, Nov. 1999.

[43] J. Wen, S. Cheng, and O. P. Malik, "A synchronous generator fuzzy excitation controller optimally designed with a genetic algorithm," IEEE Trans. Power Syst., vol. 13, pp. 884-889, Aug. 1998.

[44] C.-W. Liu, M.-C. Su, S.-S. Tsay, and Y.-J. Wang, "Application of a novel fuzzy neural network to real-time transient stability swings prediction based on synchronized phasor measurements," IEEE Trans. Power Syst., vol. 14, pp. 685-692, May 1999.

[45] A. L. B. do Bomfim, G. N. Taranto, and D. M. Falcano, "Simultaneous tuning of power system damping controllers using genetic algorithms," IEEE Trans. Power Syst., vol. 15, pp. 163-169, Feb. 2000.

[46] R. Segal, M. L. Kothari, and S. Madnani, "Radial basis function (RBF) network adaptive power systems stabilizer," IEEE Trans. Power Syst., vol. 15, pp. 722-727, May 2000.

[47] H.-J. Cho and J.-K. Park, "An expert system for fault selection diagnosis of power systems," IEEE Trans. Power Syst., vol. 12, pp. 342-348, Feb. 1997.

[48] W. Charytoniuk, E. D. Box, W.-J. Lee, M.-S. Chen, P. Kotas, and P. V. Olinda, "Neural-network-based demand forecasting in a deregulated environment," IEEE Trans. Ind. Applicat., vol. 36, pp. 893-898, May/June 2000.

[49] K.-H. Kim, H.-S. Youn, and Y.-C. Kang, "Short-term load forecasting for special days in anomalous load conditions using neural networks and fuzzy inference method," IEEE Trans. Power Syst., vol. 15, pp. 459-565, May 2000.

[50] T. Iokibe, M. Koyama, and N. Taniguchi, "Industrial applications of short-term prediction on chaotic time series by local fuzzy reconstruction method," in Proc. First Int. Conf. Knowledge-Based Intelligent Electronic Systems, Adelaide, Australia, 1997, pp. 126-130.

[51] I. F. MacGill and R. J. Kaye, "Decentralized coordination of power system operation using dual evolutionary programming," IEEE Trans. Power Syst., vol. 14, pp. 112-119, Feb. 1999.

[52] M. A. Matos, N. D. Hatziargyriou, and J. A. P. Lopes, "Multi-contingency steady state security evaluation using fuzzy clustering techniques," IEEE Trans. Power Syst., vol. 15, pp. 177-183, Feb. 2000.

[53] K. O. Wong and J. Yuryevich, "Evolutionary-programming-based algorithm for environmentally-constrained economic dispatch," IEEE Trans. Power Syst., vol. 13, pp. 301-306, May 1998.

[54] C. W. Richter and G. B. Sheble, "A profit-based unit commitment GA for the competitive environment,," IEEE Trans. Power Syst., vol. 15, pp. 715-721, May 2000.

[55] S.-J. Huang and C.-L. Huang, "Application of genetic-based neural networks to thermal unit commitment," IEEE Trans. Power Syst., vol. 12, pp. 654-660, May 1997.

[56] E. L. da Silva, H. A. Gil, and J. M. Areiza, "Transmission network expansion planning under an improved genetic algorithm," IEEE Trans. Power Syst., vol. 15, pp. 1168-1175, Aug. 2000.
[57] Y.-L. Chen, "An interactive fuzzy-norm satisfying method for multi-objective reactive power sources planning," IEEE Trans. Power Syst., vol. 15, pp. 1154-1160, Aug. 2000.

[58] M. E. El-Hawary, Ed., Electric Power Applications of Fuzzy Systems. Piscataway, NJ: IEEE Press, 1998.

[59] M. A. EL-Sharkawi, "Role of soft computing in power systems," in Proc. IEEE Int. Workshop Soft Computing in Industry, Muroan, Japan, 1996, pp. 9-14.

[60] K. Hirota and W. Pedrycz, "Fuzzy computing for data mining," Proc. IEEE, vol. 87, pp. 1575-1600, Sept. 1999.

[61] (2000) Improving power station performance with data mining at ICI chemicals and polymers. WWW page, Copyright 1998 Knowledge Process Software Limited [Online]. Available: http://www.enprotelligence.com/pages/case_ici.htm

[62] L.-R. Lin and H.-P. Huang, "Integrating fuzzy control of the dexterous National Taiwan University (NTU) hand," IEEE/ASME Trans. Mechatronics, vol. 1, no. 3, pp. 216-229, 1996.

[63] K. Kiguchi and T. Fukuda, "Position/force control of robot manipulators for geometrically unknown objects using fuzzy neural networks," IEEE Trans. Ind. Electron., vol. 47, pp. 641-649, June 2000.

[64] T. Fukuda and N. Kubota, "An intelligent robotic system based on a fuzzy approach,” Proc. IEEE, vol. 87, pp. 1448-1470, Sept. 1999.

[65] P. Baranyi, I. Nagy, P. Korondi, and H. Hashimoto, "General guiding model for mobile robots and its complexity reduced neuro-fuzzy approximation," in Proc. IEEE Int. Conf. Fuzzy Systems, San Antonio, TX, 2000, pp. 1029-1032.

[66] A. Ishiguro, Y. Shirai, T. Kondo, and Y. Uchikawa, "Immunoid: An architecture for behavior arbitration based on the immune networks," in Proc. Int. Conf. Intelligent Robotics and Systems, Osaka, Japan, 1996, pp. 1730-1738.

[67] H. Katagiri, K. Hirasawa, and J. Hu, "Dynamics of multi-agent systems by RasID learning," in Proc. IEEE Int. Conf. Systems, Man, and Cybernetics, Tokyo, Japan, 1999, pp. III-233-238.

[68] N. Kohata, T. Yamaguchi, M. Takahide, T. Baba, and H. Hashimoto, "Dynamic formation on mobile agents and its evolutionary parallel computation," in Proc. IEEE Int. Conf. Systems, Man, and Cybernetics, Tokyo, Japan, 1999, pp. I-272-277.

[69] H. Ushida, T. Yamaguchi, and T. Takagi, "Fuzzy-associative-memory-based knowledge construction with an application to a human-machine interface," IEEE Trans. Ind. Electron., vol. 46, pp. 851-860, June 1999.

[70] H. Takagi, S. Kamohara, and T. Takeda, "Introduction of soft computing techniques to welfare devices," in Proc. IEEE Midnight-Sun Workshop on Soft Computing in Industrial Applications, Kuusamo, Finland, 1999, pp. 116-121.

[71] N. Kubota, Y. Nojima, N. Baba, F. Kojima, and T. Fukuda, "Evolving pet robot with emotional model," in Proc. IEEE Conf. Evolutionary Computation, San Diego, CA, 2000, pp. 1231-1237.

[72] C. G. Atkeson, J. G. Hale, F. Pollick, M. Riley, S. Kotosaka, S. Schaal, T. Shibata, G. Tevatia, A. Ude, S. Vijayakumar, and M. Kawato, "Using humanoid robots to study human behavior," IEEE Intell. Syst., vol. 15, no. 4, pp. 46-56, 2000.

[73] T. Iokibe and Y. Fujimoto, "Failure diagnosis by trajectory parallel measure on attractor," in Proc. IEEE World Conf. Computational Intelligence, Anchorage, AK, 1998, pp. 194-1999.

[74] X. Li, A. Djordjevic, and P. K. Venuvinod, "Current-sensor-based feed cutting force intelligent estimation and tool wear condition monitoring," IEEE Trans. Ind. Electron., vol. 47, pp. 697-702, June 2000.

[75] G. G. Yen and K.-C. Lin, "Wavelet packet feature extraction for vibration monitoring," IEEE Trans. Ind. Electron., vol. 47, pp. 650-667, June 2000.

[76] D. Kim, "An implementation of fuzzy logic controller on the reconfigurable FPGA system," IEEE Trans. Ind. Electron., vol. 47, pp. 703-715, June 2000.

[77] L. A. Zadeh, "From computing with numbers to computing with words-From manipulation of measurements to manipulation of perceptions," IEEE Trans. Circuits Syst., vol. 45, pp. 105-119, Jan. 1999.

[78] D. B. Fogel, Evolutionary Computation-Toward a New Philosophy of Machine Intelligence. Piscataway, NJ: IEEE Press, 2000.

[79] Y. Dote, "Soft computing in computational intelligence and information/intelligent system," in Proc. IEEE Int. Workshop on Soft Computing in Industry, Muroran, Japan, 1999, pp. 66-71. 
[80] C.-S. Fahn, K.-T. Lan, and Z.-B. Chen, "Fuzzy rules generation using new evolutionary algorithms combined with multilayer perceptrons," IEEE Trans. Ind. Electron., vol. 46, pp. 1103-1113, Dec. 1999.

[81] D. R. Seidl, S.-L. Lam, J. A. Putman, and R. D. Lorentz, "Neural network compensation of gear backlash hysteresis in position-controlled mechanisms," IEEE Trans. Ind. Applicat., vol. 31, pp. 1475-1483, Nov./Dec. 1995.

[82] M. R. Popovic, D. M. Gorinevsky, and A. A. Goldenberg, "Highprecision positioning of a mechanism with nonlinear friction using a fuzzy logic pulse controller," IEEE Trans. Contr. Syst. Technol., vol. 8, pp. 151-158, Jan. 2000.

[83] S.-S. Ku, U. Pinsopon, S. Cetinkunt, and S. Nakamura, "Design, fabrication, and real-time neural network control of a three-degrees-offreedom nanopositioner," IEEE/ASME Trans. Mechatron., vol. 5, pp. 273-280, Sept. 2000.

[84] G. E. Cook, R. J. Barnett, K. Anderson, and A. M. Strauss, "Weld modeling and control using artificial neural networks," IEEE Trans. Ind. Applicat., vol. 31, pp. 1484-1491, Nov./Dec. 1995.

[85] F.-J. Lin, R.-J. Wai, C.-H. Lin, and D.-C. Liu, "Decoupled stator-flux-oriented induction motor drive with fuzzy neural network uncertainty observer," IEEE Trans. Ind. Electron., vol. 47, pp. 356-367, Apr. 2000.

[86] P. Z. Grabowski, M. P. Kazmierkowski, B. K. Bose, and F. Blaabjerg, "A simple direct-torque neuro-fuzzy control of PWM-inverter-fed induction motor drive," IEEE Trans. Ind. Electron., vol. 47, pp. 863-870, June 2000

[87] L. Ben-Brahim, S. Tadakuma, and A. Akdag, "Speed control of induction motor without rotational transducers," IEEE Trans. Ind. Applicat., vol. 35, pp. 844-850, July/Aug. 1999.

[88] A. D. Cheok and N. Ertugrul, "Use of fuzzy logic for modeling, estimation, and prediction in switched reluctance motor drives," IEEE Trans. Ind. Electron., vol. 46, pp. 1207-1224, Dec. 1999.

[89] Y.-Y. Zou and S.-Y. Lin, "Fuzzy-tuning current-vector control of a three-phase PWM inverter for high-performance AC drives," IEEE Trans. Ind. Electron., vol. 45, pp. 782-791, Oct. 1998.

[90] V. S. C. Raviraji and P. C. Sen, "Comparative study of proportionalintegral, sliding mode, and fuzzy logic controllers for power converters," IEEE Trans. Ind. Applicat., vol. 33, pp. 518-524, Mar./Apr. 1997.

[91] R. W. Pretorius, I. S. Shaw, and J. D. van Wyk, "A neural-networkbased controller for the cost-effective operation of a hybrid compensator for conactiva power," IEEE Trans. Ind. Electron., vol. 47, pp. 120-1227, Dec. 2000.

[92] J. O. P. Pinto, B. K. Bose, L. E. B. da Silva, and M. P. Kazmierkowski, "A neural-network-based space-vector PWM controller for voltage-fed inverter induction motor drive," IEEE Trans. Ind. Applicat., vol. 36, pp. 1628-1636, Nov./Dec. 2000.

[93] D. F. Akhmetov and Y. Dote, "General parameter approach for signal processing," J. Appl. Fast Signal Process., vol. 1, no. 1, pp. 25-30, 1997.

[94] M. S. Shaikh and Y. Dote, "An empirical study on fault diagnosis for nonlinear time series using linear regression method and FIR network," Trans. Inst. Elect. Eng. Jpn. C, vol. 120-C, no. 10, pp. 1435-1440, 2000.

[95] P. V. Goode and M.-Y. Chow, "Using a neural/fuzzy system to exact heuristic knowledge of incipient faults in induction motors-application," IEEE Trans. Ind. Electron., vol. 42, pp. 139-145, Apr. 1995.

[96] D. Fussel and R. Isermann, "Hierachical motor diagnosis utilizing structural knowledge and a self-learning neuro-fuzzy scheme," IEEE Trans. Ind. Electron., vol. 47, pp. 1070-1077, Oct. 2000.

[97] T. J. MacAvoy, "Application of neural networks in the chemical process industries," in Proc. IEEE Int. Workshop on Soft Computing in Industry, Muroran, Japan, 1993, pp. 2-9.

[98] H. N. Koivo, "Neural networks in automation-fault diagnosis and control," in Proc. IEEE Int. Workshop on Soft Computing in Industry, Muroran, Japan, 1993, pp. 10-17.

[99] Y. Maki and K. A. Loparo, "A neural-network approach to fault detection and diagnosis in industrial processes," IEEE Trans. Contr. Syst. Technol., vol. 5, pp. 529-541, Nov. 1997.

[100] Y.-Z. Lu, M. He, and C.-W. Xu, "Fuzzy modeling and expert optimization control for industrial processes," IEEE Trans. Contr. Syst. Technol., vol. 5, p. 212, Jan. 1997.

[101] T. Iwasa, N. Morizumi, and S. Omatu, "Temperature control in a batch process by neural networks," in Proc. IEEE Int. Conf. Neural Networks, Anchorage, AK, 1998, pp. 992-995.
[102] B. Schenker and M. Agarwal, "Predictive control of a bench-scale chemical reactor based on neural-network models," IEEE Trans. Contr. Syst. Technol., vol. 6, pp. 388-400, May 1998.

[103] D. Sbarbaro, J. P. Segovia, S. Alcozer, and J. Gonzales, "Applications of radial basis network technology to process control," IEEE Trans. Contr. Syst. Technol., vol. 8, pp. 14-22, Jan. 2000.

[104] R. H. Kewley, M. J. Embrechts, and C. Breneman, "Data strip mining for the virtual design of pharmaceuticals with neural networks," IEEE Trans. Neural Networks, vol. 11, pp. 668-679, May 2000.

[105] J. Scharcanski and C. T. J. Dodson, "Neural network model for paper-forming process," IEEE Trans. Ind. Applicat., vol. 33, pp. 826-839, May/June 1997.

[106] P. Viljamaa, H. Peltonen, and H. N. Koivo, "Target value computing in paper machine grade changes by fuzzy system," in Proc. IEEE Int. Conf. Fuzzy Systems, San Antonio, TX, 2000, pp. 105-109.

[107] M. Kayama, Y. Sugita, Y. Morooka, and S. Fukuoka, "Distributed diagnosis system combining the immune network and learning vector quantization," in Proc. IEEE Int. Conf. Industrial Electronics, Orlando, FL, 1995, pp. 1531-1536.

[108] G. Bloch, F. Sirou, V. Eustache, and P. Fatrez, "Neural intelligent control for a steel plant," IEEE Trans. Neural Networks, vol. 8, pp. 910-918, July 1997.

[109] D. F. Garcia, J. M. Lopez, F. J. Suarez, J. Garcia, F. Obeso, and J. A. Gonzalez, "A novel real-time fuzzy-based diagnostic system of roll eccentricity influence in finishing hot strip mills," IEEE Trans. Ind. Applicat., vol. 34, pp. 1342-1349, Nov./Dec. 1998.

[110] M. Dussud, S. Galichet, and L. P. Foulloy, "Application of fuzzy logic control for continuous casting mold level control," IEEE Trans. Contr. Syst. Technol., vol. 6, pp. 246-256, Mar. 1998.

[111] (2000) Oil and gas-data mining to improve process performance. WWW page, Copyright 2000 Knowledge Process Software Limited [Online]. Available: http://www.enprotelligence.com/pages/case_gas.htm

[112] H. Innami, H. Tsutui, and J. Nishimura, "Application of soft computing in process industry" (in Japanese), in J. Soc. Instrum. Contr. Eng. Jpn. (Special Issue on Soft Computing as Break Through), K. Hirota, Ed., 2000, vol. 39, pp. 184-187.

[113] C. B. Kim, K. A. Seong, H. Lee-Kwang, and J. O. Kim, "Design and implementation of a fuzzy elevator group control system," IEEE Trans. Syst., Man, Cybern. A, vol. 28, pp. 277-287, May 1998.

[114] A. Fujino, T. Tobita, K. Segawa, K. Yoneda, and A. Togawa, "An elevator group control system with floor-attribute control method and system optimization using genetic algorithm," IEEE Trans. Ind. Electron., vol. 44, pp. 546-552, Aug. 1997.

[115] J. Niittymaki and R. Nevala, "Fuzzy logic two-phase traffic signal control for coordinated one-way streets," in Soft Computing in Industrial Applications, Y. Suzuki, S. Ovaska, T. Furuhashi, R. Roy, and Y. Dote, Eds. London, U.K.: Springer-Verlag, 2000, pp. 107-116.

[116] G. K. H. Pang, K. Takahashi, T. Yokota, and H. Takenaga, “Adaptive route selection for dynamic route guidance system based on fuzzy-neural approaches," IEEE Trans. Veh. Technol., vol. 48, pp. 2028-2040, Nov. 1999.

[117] Y.-P. Kuo and T.-H. S. Li, "GA-based fuzzy PI/PD controller for automotive active suspension system," IEEE Trans. Ind. Electron., vol. 46, pp. 1051-1056, Dec. 1999.

[118] K. Hayashi, Y. Shimizu, Y. Dote, A. Takayama, and A. Hirako, "Neuro fuzzy transmission control for automobile with variable loads," IEEE Trans. Contr. Syst. Technol., vol. 3, pp. 49-53, Jan. 1995.

[119] S. Matsumura, S. Omatu, and H. Higasa, "Improvement of speed control performance using PID type neuro-controller in an electric vehicle system," in Proc. IEEE Int. Conf. Neural Networks, vol. 4, Orlando, FL, 1994, pp. 2649-2654.

[120] H. Hotsmann, O. Nelles, C. Halfmann, and R. Isermann, "Vehicle dynamics simulation based on hybrid modeling," in Proc. IEEE/ASME Int. Conf. Advanced Intelligent Mechatronics, Atlanta, GA, 1999, pp. 1014-1019.

[121] C. S. Chang and S. S. Sim, "Optimizing train movements through coast control using genetic algorithms," Inst. Elect. Eng. Proc. Power Applicat., vol. 144, no. 1, pp. 65-73, 1997.

[122] J. N. K. Liu and K. Y. Sin, "Fuzzy neural networks for machine maintenance in mass transit railway system," IEEE Trans. Neural Networks, vol. 8, pp. 932-941, July 1997.

[123] G. M. P. O'Hare and N. R. Jennings, Eds., Foundations of Distributed Artificial Intelligence. New York: Wiley, 1996. 


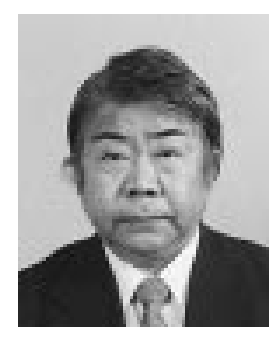

Yasuhiko Dote received the B.S. degree in electrical engineering from Muroran Institute of Technology, Muroran, Japan, in 1963, and the M.S. and Ph.D. degrees from the University of Missouri, Columbia, MO, in 1972 and 1974, respectively.

From 1963 to 1973, he was with Yaskawa Electric Manufacturing Company, Ltd., Japan. In 1974, he was a visiting engineer at the Massachusetts Institute of Technology, Cambridge, MA. He was a visiting researcher at the University of Missouri, Columbia, MO, in 1979 and at the Engineering Science Department of Oxford University, U.K., in 1980. In 1983, he was a Visiting Professor and Consultant at the United Nations Water and Power Research Station, Puna, India. In 1989, he served as a Visiting Professor at the Power Electronics Application Center, University of Tennessee, Knoxville, TN. From April 1999 through March 2004, he is a Docent (Soft Computing Methods in Industrial Applications) at Helsinki University of Technology, Finland. He was a Visiting Professor at Helsinki University of Technology, Department of Electrical and Communications Engineering, from September 1 to December 31, 2000. At present, he is a Professor of Computer Science and Systems Engineering at Muroran Institute of Technology, Muroran, Japan. He established the World Federation of Soft Computing with his research colleagues under the advice of Dr. L. A Zadeh in 1999. He has published over 60 technical papers on motor drive systems and intelligent control and has five books on motion control on his credit. His research interest lies in the field of intelligent control methods applied to motor drive and motion control systems.

Dr. Dote was the Chairman of the Modern Control Theory Application Survey Committee in Institute of Electrical Engineers of Japan for three years. He was the Chairman of the Soft Computing Application to Industry Survey Committee in 1995. He was a General Chairman of the IEEE International Workshop on Neuro Fuzzy Control, held in 1993 at Muroran. He was also the General Chairman of the International Workshops on Soft Computing in Industry, Muroran, Japan, 1996, and 1999. He was a Co-Chair of the International Workshop on Soft Computing in Engineering Design and Manufacturing on the Internet during 1998 and 1999. He was an Associate Editor at Large of the IEEE TRANSACTIONS ON INDUSTRIAL ELECTRONICS. $\mathrm{He}$ is a Member of IEE, Japan.

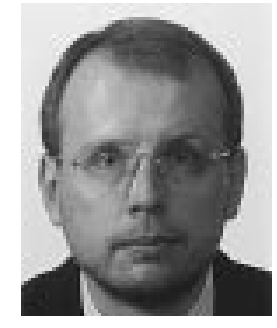

Seppo J. Ovaska (Senior Member, IEEE) received the M.Sc. degree in electrical engineering from Tampere University of Technology, Finland, the Lic.Sc. degree in computer science and engineering from Helsinki University of Technology, Finland, and the D.Sc. degree in electrical engineering from Tampere University of Technology in 1980, 1987, and 1989, respectively.

He is currently a Professor of Industrial Electronics and Vice Chair of the Department of Electrical and Communications Engineering, Helsinki University of Technology. Before joining Helsinki University of Technology in 1996, he was a Professor of Electronics at Lappeenranta University of Technology, Finland. From 1980 to 1992, he held engineering, research, and R\&D management positions with Kone Elevators and Nokia Research Center, both in Finland and the U.S. In the summer of 1999, he was a visiting scholar at Muroran Institute of Technology, Japan, and in the summers of 2000 and 2001, at Virginia Polytechnic Institute and State University. His research interests are in soft computing, fault diagnosis, control, and signal processing. During his career, he has authored or co-authored over 150 technical papers in peer-reviewed journals and international conferences. He co-edited Soft Computing in Industrial Applications (Springer, 2000), and holds nine patents in the area of systems and control.

Dr. Ovaska is an Associate Editor of the IEEE TRANSACTIONS ON INDUSTRIAL ELECTRONICS. He also served as an Associate Editor of the IEEE TRANSACTIONS ON INSTRUMENTATION AND MEASUREMENT (1996-1998). He is the Coordinating Chair of the "Systems" Group of the IEEE SMC Technical Committees, as well as an active member of the IEEE SMC Industrial Applications Technical Committee. In addition, he is an Elected Member of the IEEE SMC Administrative Committee. He was the Founding General Chair of the 1999 IEEE Midnight-Sun Workshop on Soft Computing Methods in Industrial Applications. In addition, he was the General Chair of the 5th Online World Conference on Soft Computing in Industrial Applications. He is a recipient of the Outstanding Contribution Award of the IEEE Systems, Man, and Cybernetics Society. He is listed in Marquis Who's Who in Science and Engineering. 